\title{
La revista Mampato y las músicas: conceptos y prácticas musicales en una publicación infantil chilena (1968-1978)1
}

\author{
Mampato Magazine and music: concepts and musical \\ practices in a chilean children's publication (1968-1978)
}

\author{
por \\ Cristián Guerra Rojas \\ Universidad de Chile
}

En este artículo se presenta la revista infantil chilena Mampato (1968-1978) como fuente de interés para estudios musicológicos y culturales. Mediante la revisión exhaustiva de esta publicación y el examen preliminar de sus distintas secciones, se muestra que esta revista puede y debe ser considerada como una fuente para estudiar distintos aspectos musicales (prácticas, repertorios, nociones, conceptos) que remiten tanto a representaciones socialmente compartidas de las músicas en la cultura occidental como a un contexto sociohistórico concreto: Chile entre 1968 y 1978. Y esto no solo en el marco de la transmisión didáctica de conocimientos, sino en el incentivo a la práctica del escuchar y hacer música.

Palabras clave: Música en Chile 1968-1978, Mampato, música e historietas, música e infancia.

In this article, the Chilean children's magazine Mampato (1968-1978) is presented as a source of interest for musicological and cultural studies. Through the exhaustive review of this publication and the preliminary examination of its different sections, it is shown that this magazine can and should be considered as a source to study different aspects of musics (practices, repertoires, notions, concepts) that refer both to socially shared music representations in Western culture as a concrete sociohistorical context, Chile between 1968 and 1978. And this not only within the framework of the didactic transmission of knowledge, but in the incentive to the practice of listening and making music.

Keywords: Music in Chile 1968-1978, Mampato, music and comics, music and childhood.

\section{ANTECEDENTES}

En las últimas décadas se han desarrollado distintos estudios acerca de las revistas infantiles y juveniles, especialmente su vínculo con la formación y educación de niñas, niños y

1 Este artículo constituye la versión elaborada de un trabajo presentado como ponencia en el II Congreso de la Asociación Regional para América Latina y el Caribe de la Sociedad Internacional de Musicología, ARLAC/IMS, Universidad Alberto Hurtado, Santiago de Chile, 12 al 16 de enero de 2016. Asimismo, este texto se enmarca dentro de una línea de investigación que he procurado desarrollar en torno a las relaciones entre músicas e historietas, cuyos resultados parciales he presentado en ponencias expuestas en diferentes instancias académicas. 
adolescentes. El énfasis principal ha estado, en consecuencia, en enfoques historiográficos y pedagógicos. En ese rubro se pueden recordar varios trabajos acerca de revistas infantiles en el México decimonónico ${ }^{2}$ y en el posrevolucionario ${ }^{3}$, en la España franquista ${ }^{4}$ y en Argentina ${ }^{5}$. Además hay estudios de casos como las revistas Chanchito de Colombia ${ }^{6}$ y Billiken de Argentina ${ }^{7}$. Existen también tesis del ámbito de las comunicaciones que han abordado las revistas como consumo ${ }^{8}$, su influencia en la infancia ${ }^{9}$, o como cruce entre cultura popular y cultura infantil ${ }^{10}$. A esto hay que agregar varios estudios acerca de las historietas publicadas en estas revistas, como el caso de la construcción de género en Patoruzito, Gaturro y otras publicaciones $^{11}$, de las implicaciones sociopolíticas y sus vínculos con la modernidad en Mampato ${ }^{12}$ o de revistas ecuatorianas usadas como material didáctico en la etapa escolar ${ }^{13}$.

Sin embargo, hay escasas consideraciones acerca de la dimensión musical en estas revistas o en sus contenidos. Así por ejemplo, en su tesis acerca de historietas y humor gráfico en publicaciones de Sevilla, Barrero menciona solo de paso "la fórmula de mezclar música pop y tebeos" en las revistas Aqui Marilín y Guendalina ${ }^{14}$. Debido al impacto que estos artefactos culturales han tenido en la formación de generaciones de niñas, niños y adolescentes en los países latinoamericanos (y más allá), es extraño que hasta ahora no se haya tomado en cuenta con mayor detenimiento las maneras en que prácticas, repertorios o nociones acerca de las músicas ${ }^{15}$ se han plasmado en sus secciones, incluidas ciertamente las historietas.

Ahora bien, al hacer esta afirmación no me refiero a estudios en torno a aquellas revistas infantiles o juveniles donde lo musical ocupa un lugar central ${ }^{16}$. Pero en lo que atañe a revistas que no están dedicadas a este tema de un modo prioritario, dichos estudios no existen o no he tenido acceso o conocimiento de ellos hasta ahora. En este aspecto, el presente trabajo aspira a ser un aporte, enfocándome en el caso particular de la revista chilena Mampato. Después de revisar cada número de esta publicación y examinar sus distintas secciones ${ }^{17}$, quiero mostrar que esta revista puede y debe ser considerada como una fuente para estudiar distintos aspectos musicales (prácticas, repertorios, nociones, conceptos) que remiten tanto a un imaginario socialmente compartido de las músicas en la cultura occidental como a un contexto sociohistórico concreto: Chile entre 1968 y 1978. Y esto no solo en el marco de la transmisión didáctica de conocimientos, sino en el incentivo a la práctica del escuchar y hacer música.

2 Escalante 2015: 161.

3 Jackson 2015.

${ }^{4}$ Ballesteros 2018.

Olivera 2014.

6 Ospina 2017; Peters y Trujillo 2018; Robledo 2004.

7 Bontempo 2012; Falabella 2009; Falabella y Tomino 2007; Tessada 2009.

8 Arroyo 2006; Espiño 2014.

9 González 2015.

10 Block 2000.

11 Pascual 2018.

12 Castillo 2013; Castillo 2018; Rojas 2012b, 2012c.

13 Alvarracín y González 2015.

14 Barrero 2015: 372, 394.

15 Opto por el plural "músicas" para subrayar la necesaria apertura a la diversidad de lenguajes musicales (Mendívil 2016: 17).

16 Como el caso de Lamadrid 2014 acerca de Ritmo.

17 Para ello ha sido fundamental la labor realizada por la "generación mampatina", especialmente mediante el blog Yo soy de la generación Mampato (http://generacionmampato.blogspot.com/) creado en 2008 y administrado por "Mayoneso". En este sitio se han podido localizar todas las ediciones digitalizadas de la revista, comentarios y otros materiales cruciales para el presente estudio. 


\section{LA REVISTA MAMPATOY SU CONTEXTO}

La importancia de la década de 1960 ha sido destacada en múltiples estudios y reflexiones. En un mundo ya en vías de la hoy llamada globalización o mundialización, cuando la tensión entre las dos superpotencias que pugnaban por la hegemonía mundial (Estados Unidos de América y la Unión de Repúblicas Socialistas Soviéticas) afectaba la vida política, social y cultural de distintos países en diferentes continentes, hubo lugar para expresiones de honda preocupación y también de esperanza en un cambio sociocultural profundo. Chile y Latinoamérica no estuvieron ajenos a esas tensiones, preocupaciones y esperanzas, las que alcanzaron un punto climático en 1968 con movimientos que afectaron a todo el mundo globalizado. Como dice Lamadrid ${ }^{18}$ :

Las “tormentas de 1968”, extendidas desde Praga hasta México y que pasaron por el sur de América Latina, expresaban la impaciencia ante la demora en las transformaciones radicales que se venían anunciando desde principios de la década, y mostraban la fragilidad de sistemas político-sociales aparentemente sólidos. En América Latina revivieron las esperanzas revolucionarias aunque, retrospectivamente, sea posible ver que anunciaban la curva descendente".

En Chile la población creció de 6 a 9 millones y medio entre 1950 y 1970, décadas en que la migración del campo a la ciudad llevó a que la población urbana alcanzara el $75 \%$ en 1970. En 1964 una fuerza política emergente, la Democracia Cristiana, alcanzó la presidencia de la república con Eduardo Frei Montalva a la cabeza. Su gobierno acogió reivindicaciones como la nacionalización del cobre, la Reforma Agraria y una reforma educacional que buscó ampliar significativamente la cobertura escolar, mientras se expandía el consumo y el acceso, entre otros ámbitos, a los medios de comunicación como diarios, revistas, cine, radio y televisión ${ }^{19}$. En este marco, el crecimiento del poder adquisitivo de sectores juveniles tuvo directa relación con la emergencia e instalación de nuevos géneros en el estrato de las músicas populares urbanas: rock, Nueva Ola, neofolclor y Nueva Canción Chilena.

En el terreno editorial, en 1956 Agustín Edwards Budge, dueño del periódico El Mercurio de Santiago, creó la editorial Lord Cochrane para aprovechar maquinaria que quedaba en desuso. Al año siguiente esta editorial pasó a manos de su hijo Roberto Edwards Eastman (n. 1937), el que comenzó a incursionar en el área de las publicaciones periódicas para competir con la poderosa Editorial Zig-Zag. Si bien en el campo de las historietas, pese a un convenio logrado con King Features Syndicate, no obtuvo el éxito esperado, se obtuvo un buen resultado con tres revistas dirigidas a sectores específicos: Ritmo de la Juventud (1965) a los lectores/as juveniles, Paula (1967) hacia el público adulto femenino y Mampato (1968) hacia niñas, niños y adolescentes ${ }^{20}$.

El gestor de la revista Mampato fue el arquitecto y artista visual Eduardo Armstrong Aldunate (1931-1973), el que presentó a Edwards un proyecto cuyo título original era Los Pecosos. Armstrong tenía como referencia revistas de Zig-Zag como El Peneca (1908-1960) o El Cabrito (1941-48), además de revistas europeas como Tintin y Spirou, la argentina Billiken y también un suplemento de El Mercurio llamado Mampato, cuyos derechos editoriales habían sido traspasados a Lord Cochrane ${ }^{21}$. Edwards se entusiasmó con el proyecto pero

18 2014: 58.

19 Lamadrid 2014: 65; Rojas 2016: 61.

20 Rojas 2016: 75-76.

21 Rojas 2010: 556; Vega Etcheverry 2018: 156. 
sugirió adoptar el título de aquel suplemento, y de este modo apareció el primer número de Mampato el 30 de octubre de 1968, iniciando una trayectoria que se prolongaría diez años. Inicialmente su frecuencia fue quincenal, pero a partir del $\mathrm{N}^{\circ} 64$ de 1971 adoptó frecuencia semanal. En el $\mathrm{N}^{\circ} 2$, el propio personaje principal, Mampato ${ }^{22}$, presentaba su revista ${ }^{23}$ :

“:Por fin se han acordado de nosotros! Habían transcurrido veinte años desde que desapareció la última revista para niños ${ }^{24}$. Pero finalmente, un grupo de amigos se reunió con la idea de hacer una totalmente adaptada a nuestros tiempos: Que nos entretuviera, nos enseñara y nos ayudara en los problemas del colegio con la participación de todos".

El público objetivo era niños y niñas en etapa escolar entre 7 y 14 años, aproximadamente. Contenía en lo principal historietas y secciones didácticas, lo que podríamos denominar "entretención informada" o "entretención didáctica". De este modo, Mampato se acerca a lo que Juan Diego Pérez ${ }^{25}$ caracteriza como el "modelo francés" de las revistas juveniles:

"Son auténticamente educativas siempre de acuerdo con el segmento de edad al que vayan dirigidos, sus contenidos fomentan el interés por la lectura de textos y de imágenes (suelen dar cabida a los comics). Abordan temas muy diversos, desde la narrativa a las ciencias, la naturaleza, la actualidad en sus diversos aspectos e incluso el arte”.

El éxito de Mampato se debió no solo a la creatividad y sensibilidad de Armstrong ${ }^{26}$ o al respaldo de Edwards, sino además a la capacidad del primero en reunir un equipo de profesionales (periodistas, redactores y artistas) que se hicieran cargo de las diferentes secciones que se concibieron. Entre ellos hay que mencionar a la periodista y escritora Isabel Allende Llona (n. 1942), a los dibujantes Óscar Vega Etcheverry (“Oskar”, 1945-2007) y Temístocles Lobos Aguirre ("Themo", 1928-2012) y a la periodista Cecilia Eyzaguirre Edwards (n. 1934) ${ }^{27}$. Como afirma Jorge Rojas ${ }^{28 .}$

"La revista Mampato buscó ofrecer al mismo tiempo entretención, contenidos escolares y principios morales a sus lectores. De forma consciente, a veces, pero también reproduciendo creencias dominantes en algunos sectores, a través de sus páginas se reprodujeron valores por distintos medios, en sus diversas secciones. A veces, los contenidos fueron explícitos y en otros casos, se filtraron de una manera más sutil e indirecta”.

En principio, esos "principios morales" o "creencias dominantes" se pueden vincular con la clase social de la que provenían Edwards o Armstrong. Pero también se pueden entender como aquellos que sustentaban de modo tácito o explícito al proyecto político,

22 Para referirme a la revista uso el nombre en cursivas (Mampato) y al referirme a la historieta o a su protagonista, el nombre aparece en letras normales (Mampato).

23 Mampato $\mathrm{N}^{\circ} 2$ (13 de noviembre, 1968): 3. En adelante se omitirá el título de la revista en las restantes referencias.

24 Seguramente se refiere a El Cabrito, cuyo último número se publicó exactamente veinte años antes, en 1948.

25 Pérez 1999.

26 Según su hijo Jorge Armstrong Irarrázaval, la revista Mampato era su "diario de vida”, "el dibujo definitivo de sus sueños, sus viajes, sus héroes, sus aventuras” (Armstrong 2015: 9).

27 Prima en cuarto grado de Roberto Edwards.

28 Rojas 2012c. 
educacional y cultural promovido por el gobierno de Frei ${ }^{29}$, profundizados o radicalizados posteriormente en el gobierno de Salvador Allende Gossens y la Unidad Popular (19701973). Es lo que ocurrió, por ejemplo, con la Reforma Agraria, además de otras iniciativas que apuntaban a transformaciones estructurales profundas en la sociedad chilena, con mayor participación y acceso a las decisiones políticas, a la educación y a los bienes culturales por parte de los sectores sociales que hasta entonces habían sido menos favorecidos. Sin embargo, desde el inicial clima de fiesta y esperanza que se vivió en los albores del gobierno de la UP se llegó a una polarización sociopolítica que alcanzaría su trágico desenlace el 11 de septiembre de 1973.

Durante el gobierno de la UP, la Editorial Lord Cochrane continuó funcionando y publicando sus tres revistas emblemáticas, Ritmo, Paula y Mampato. Esta última alcanzó buena venta en esos años ${ }^{30}$, pese a las dificultades derivadas de la inflación creciente que incidió en el aumento progresivo de su precio de venta, desde 6 escudos $\left(\mathrm{E}^{\circ} 6\right)$ a fines de 1970 hasta $\mathrm{E}^{\circ} 100$ a fines de $1973^{31}$. La revista mantuvo su línea editorial en este período y aunque su orientación política nunca fue nítida en toda su existencia ${ }^{32}$ se puede observar ciertos énfasis que denotan, de manera consciente o no, una sintonía moderada con el proyecto sociopolítico de la UP. Es el caso de la sección "Puertas Adentro" que debutó en abril de $1972^{33}$, donde Cecilia Eyzaguirre presentaba entrevistas a niñas, niños y adolescentes de distintas clases y sectores sociales.

En los últimos meses del gobierno de Allende, la revista no pudo sustraerse completamente del enrarecimiento radical del clima sociopolítico en Chile. En este marco se publicó un reportaje acerca de actividades en el Parque O'Higgins de Santiago ${ }^{34}$ que suscitó reacciones encontradas ${ }^{35}$. Hubo cartas de lectores que se quejaban de este clima de polarización creciente ${ }^{36}$ y la misma Isabel Allende, quien debió asumir la conducción efectiva de la revista en marzo de 1973 debido a la enfermedad de Armstrong ${ }^{37}$, se pronunció en varios editoriales respecto de este tema ${ }^{38}$.

Por otra parte, el abordaje que se hacía a la realidad social en la revista ha sido calificado como conformista e incluso favorecedor de los sectores opositores al régimen de la UP39. Esto explicaría la decisión de Editora Nacional Quimantú, creada por el gobierno de Allende después de comprar la mayor parte de Zig-Zag a comienzos de 1971, de competir en el mercado editorial con sus propias publicaciones para difundir masivamente los principios y valores de la UP. Entre ellas, tres publicaciones competían por los mismos públicos

29 Ya en la sección de correo en N o 8 ([5 de febrero], 1969): 3, se anuncia que la revista comenzará a publicar materiales relacionados con el programa educacional del Ministerio de Educación.

30 Rojas 2016: 279.

31 Solo en 1973 la revista subió de $\mathrm{E}^{\circ} 25$ en marzo $\left(\mathrm{N}^{\circ} 164\right)$ a $\mathrm{E}^{\circ} 100$ en octubre $\left(\mathrm{N}^{\circ} 195\right)$, comenzando 1974 con un precio de $\mathrm{E}^{\circ} 180$ ( $\left.\mathrm{N}^{\circ} 206\right)$.

32 Rojas 2012b: 300.

$33 \mathrm{~N}^{\mathrm{o}} 117$ (12 de abril, 1972): 42-43.

$34 \mathrm{~N}^{\mathrm{o}} 155$ (3 de enero, 1973): 50-51.

$35 \mathrm{~N}^{\circ} 159$ (31 de enero, 1973): 1.

$36 \mathrm{~N}^{\circ} 169$ (11 de abril, 1973): 49.

37 Valle 2018: 88.

$38 \mathrm{~N}^{\circ} 173$ (9 de mayo, 1973): 3; $\mathrm{N}^{\circ} 175$ (23 de mayo, 1973): 3; No 181 (4 de julio, 1973): 3; ver también Rojas 2016: 416.

39 Jofré 1986: 62, Rojas 2010: 561. 
objetivos de las revistas emblemáticas de Lord Cochrane: Paloma contra Paula, Onda contra Ritmo y Cabrochico contra Mampato ${ }^{40}$.

Con el golpe de Estado del 11 de septiembre de 1973 Chile entró abruptamente a una nueva etapa en la que la dictadura militar intentó borrar todo rastro de la UP y de los cambios sociopolíticos que se había tratado de implementar. Una apertura económica propiciada en 1975 condujo al declive de la industria nacional y la televisión, férreamente controlada por el régimen, se expandió a tal punto que desplazó en influencia a todos los demás medios de comunicación masiva ${ }^{41}$.

Estos hechos, sumados al prematuro fallecimiento de Eduardo Armstrong el 7 de noviembre de 1973, repercutieron en el rumbo de la Editorial Lord Cochrane y de Mampato. Después de la salida de Isabel Allende de la dirección de la revista por razones no suficientemente esclarecidas ${ }^{42}$, una seguidilla de directores/as, cada uno/a con su propio concepto de lo que debía ser o seguir siendo la revista, asumió la conducción de Mampato: Sergio Araos Bruna (1974) ${ }^{43}$, Vittorio di Girolamo (1974-75) ${ }^{44}$, Renzo Pecchenino "Lukas" (197576) ${ }^{45}$, Isabel Wachholtz (1976-77) ${ }^{46}$ y finalmente Nicolás Velasco del Campo (1977-78) ${ }^{47}$.

En esta última etapa, a pesar de su discurso oficial conciliatorio ${ }^{48}$, la revista debió sufrir los embates de la censura oficial o extraoficial. Esto se aprecia en la suspensión temporal de la historia "Mampato y los caballeros del aire o El piloto loco" debido a la supuesta caricaturización insolente de los militares ${ }^{49}$, el forzado cambio del final de "Mampato contra

40 Aunque el público objetivo de Cabrochico parece haber sido algo menor en edad que aquel de Mampato y sus editores declaraban en su primer número (julio, 1971) que "no había pretensión de ganancias ni de competir comercialmente; la edición prácticamente sale al costo; lo importante es [...] ser una alternativa a todas las publicaciones alienantes y mixtificadoras que se siguen entregando a nuestros niños", es difícil no concebir que la crítica a las historietas hegemónicas que apareció en el suplemento para adultos de Cabrochico $\mathrm{N}^{\circ} 5$ no involucrara parcialmente a Mampato o que el personaje de Mañungo, creado por Guidú para Cabrochico, no resulte ser una especie de contrapartida del viajero pelirrojo de Editorial Lord Cochrane. Sin embargo, pese a su éxito inicial y ser una revista más modesta y barata (comenzó vendiéndose en $\mathrm{E}^{\circ}$ 3,50 y terminó en $\mathrm{E}^{\circ} 15$ un año después, siempre muy debajo del precio que alcanzó Mampato), Cabrochico terminó bajando sus ventas y fue cancelada (Mardones 2015, Rojas 2012a: 613-614; Rojas 2012b: 300 y Rojas 2016: 297-301). Curiosamente, Guidú colaboraría después en Mampato durante el régimen militar, a lo que me referiré más adelante.

41 Rojas 2016: 399.

42 Allende asumió la dirección en propiedad de Mampato a partir del No 199 (14 de noviembre, 1973) y hasta el $\mathrm{N}^{\circ} 252$ (20 de noviembre, 1974). Se ha atribuido su salida de la dirección, entre otras razones, a la portada del $N^{\circ} 226$ (22 de mayo, 1974), donde aparecen cuatro gorilas que alguien habría asociado con los integrantes de la Junta Militar.

43 Araos aparece en los créditos de la revista como representante legal de Mampato desde el No 251 (13 noviembre, 1974) hasta el No 377 (13 de abril, 1977) y como director solamente en el $N^{\circ} 253$ (27 de noviembre, 1974).

44 Desde el $\mathrm{N}^{\circ} 254$ (4 de diciembre, 1974) hasta el $\mathrm{N}^{\circ} 280$ (3 de junio, 1975).

45 Desde el $\mathrm{N}^{\circ} 281$ (10 de junio, 1975) hasta el $\mathrm{N}^{\circ} 335$ (23 de junio, 1976).

46 Desde el No 336 (30 de junio, 1976) hasta el No 380 (4 de mayo, 1977).

47 Desde el $N^{\circ} 381$ (11 de mayo, 1977) hasta el $N^{\circ} 418$ (25 de enero, 1978).

48 Esto se observa en editoriales y en el incentivo a actividades como la formación de los "clubes Mampato" (iniciativa afín a las de Tintin o Billiken) integrados por niños y niñas con propósitos de fomentar la convivencia y sociabilidad. La primera referencia a un Club Mampato aparece en 1974 ( $\mathrm{N}^{\mathrm{o}}$ 222, 24 de abril, 1974: 50).

49 Rojas 2012b: 301. Esta historia, con guion y dibujos de Themo Lobos, se empezó a publicar en el No 250 (6 de noviembre, 1974, bajo la dirección de Isabel Allende) y se interrumpió en el No 257 (23 de diciembre, 1974). Se reanudó a partir del $\mathrm{N}^{\circ} 262$ (29 de enero, 1975) hasta concluir en el $\mathrm{N}^{\circ} 267$ (5 de marzo, 1975). En el editorial del No 262 (con Vittorio di Girolamo como nuevo director) se explicó que la interrupción se debió a "razones técnicas". 
los Verdines" por sus alusiones a la tortura ${ }^{50}$, o la imposibilidad de publicar la segunda parte de la historieta "Dina y Nino en la tierra perdida de Mu", de Máximo Carvajal Belmar (1935-2006), debido a objeciones de la dirección ${ }^{51}$. Finalmente, la baja creciente de ventas de la revista, la que en su mejor momento llegó a vender 100.000 ejemplares hasta bajar a solo $7.000^{52}$, llevó a la decisión de cancelar su publicación con el $\mathrm{N}^{\mathrm{o}} 418$ (enero de 1978) ${ }^{53}$. Con la cancelación de Mampato y habiendo salido Ritmo de circulación en 1975, solo la revista Paula ha continuado publicándose hasta hoy bajo el alero de otros propietarios ${ }^{54}$.

En lo que a la relación con música se refiere, en la revista distinguimos varias secciones donde aquella ocupa regular u ocasionalmente un lugar marginal o destacado. Aquí daré cuenta preliminar de estas secciones y en todos los casos procuraré señalar las dimensiones donde el contexto político y sociohistórico de Chile en esos años se devela explícita o sutilmente, o donde se plasman referencias o representaciones de lo musical enraizadas en la cultura musical occidental.

\section{LAS MÚSICAS EN LA HISTORIETA MAMPATO}

La revista se caracterizó y es muy recordada hoy por las diferentes historietas que publicó durante los diez años de su vida, de autores tanto chilenos como extranjeros. Sin embargo, uno de los rasgos que la distingue de El Peneca es "la creación de una historieta propia y homónima centrada en las aventuras fantásticas de un escolar de clase media que dispone secretamente de una máquina del tiempo ${ }^{55}$ ". En esta sección me centraré en esta historieta principal, cuyo protagonista le da el nombre a la revista.

El personaje fue creado por Armstrong y originalmente dibujado por Óskar, tomando como referencia personajes como Astérix de Albert Uderzo (n. 1927) y René Goscinny (1926-1977), y Dennis the Menace (Daniel el Travieso) de Hank Ketcham (1920-2001).

50 Publicada desde Mampato $\mathrm{N}^{\circ} 304$ (18 de noviembre, 1975) hasta $\mathrm{N}^{\circ} 309$ (23 de febrero, 1975) y de autoría de Óskar, no debe confundirse con un relato homónimo de Themo que se publicó entre el $\mathrm{N}^{\circ} 24$ (17 de septiembre, 1969) y el $\mathrm{N}^{\circ} 34$ (3 de febrero, 1970). El desenlace original de esta historia, como lo concibió Óskar, se publicó en la recopilación Los viajes en el tiempo de Mampato (Planeta Cómic, 2018).

51 La primera parte de "Dina y Nino" se publicó entre el No 285 (8 de julio, 1975) y el No 290 (12 de agosto, 1975) de Mampato, cuando la revista era dirigida por Renzo Pecchenino. Carvajal atribuye la objeción de Wachholtz a su ignorancia acerca de la historieta y su poco respeto hacia la creación artística, ya que la segunda parte de "Dina y Nino" contenía viñetas donde aparece una chica con el torso desnudo. Esto resulta extraño al considerar que Wachholtz venía trabajando como redactora en Mampato al menos desde fines de 1973. Mayores detalles en Hasson 2014: 83, http://ergocomics. cl/wp/2006/08/cronicas-de-la-tierra-perdida-de-mu-2/ y http://bibliotecajuntoalmar.blogspot. com/2012/11/dibujantes-chilenos-y-las-portadas-en.html [consulta: 9 de noviembre, 2018 ].

52 http://terceracultura.cl/2010/04/mampato-el-mas-ceronta-de-los-setenteros/ [consulta: 9 de noviembre, 2018]. A comienzos de 1974 Mampato se vendía a $\mathrm{E}^{\circ} 180$ s ( $\mathrm{N}^{\circ}$ 206, 2 de enero de 1974) y después de un año y ocho meses alcanzó un precio de $\mathrm{E}^{\circ} 3.000$ ( $\mathrm{N}^{\circ} 293,2$ de septiembre de 1975), reconvertido a 3 pesos (\$3, cambio de moneda decretado por el gobierno) a partir del $\mathrm{N}^{\circ} 297$ (30 de septiembre de 1975). La revista terminó vendiéndose a $\$ 23$ desde el $\mathrm{N}^{\circ} 408$ (16 de noviembre de 1977) hasta su cancelación.

53 En septiembre de 1978 en El Mercurio debutó el suplemento infantil Pocas Pecas, que intentó llenar el vacío dejado por Mampato. Este suplemento se mantuvo hasta 1982 y varios integrantes del equipo de Mampato trabajaron allí.

54 A partir de junio de 2018, la revista Paula ha pasado a ser un suplemento dominical del periódico La Tercera, propiedad del grupo Copesa.

55 Castillo 2018. 
Su nombre original habría sido Félix el Aventurero, pero con el cambio de título de la revista que sugirió Edwards, adoptó el mismo nombre de la publicación ${ }^{56}$. Es un niño de unos diez años de edad cuyo verdadero nombre es Patricio, colorín, miembro de una familia de clase media con padres y una hermana menor. Asiste a una escuela pública, es muy estudioso, ilustrado e imaginativo, un verdadero niño-adulto ${ }^{57}$. En su primera aventura se explica que su sobrenombre deriva de su estatura peculiarmente pequeña ${ }^{58}$, conoce accidentalmente a Xsé, un extraterrestre con el que colabora para liberar su planeta de las garras de un tirano y como recompensa obtiene un "cinto espacio-temporal". Gracias a ese aparato extraterrestre, Mampato se convierte en un viajero que puede circular entre diversos tiempo-espacios en su pasado o en su futuro ${ }^{59}$.

Debido a que Óskar no habría podido asumir el compromiso de entregas regulares requeridas para cada edición, la historieta pasó a manos de Themo Lobos, primero a cargo solo de los dibujos pero posteriormente también del guion ${ }^{60}$. De este modo Themo terminó de definir al personaje y creó a sus dos compañeros más recordados, el cavernícola Ogú y la bella Rena del siglo 40. Por otro lado, Óskar retomó la historieta en algunas ocasiones y, aunque asumió varios de los rasgos definidos por Themo ${ }^{61}$, en los relatos de su autoría creó algo así como un universo paralelo de Mampato que no se relaciona con aquel imaginado por su colega ${ }^{62}$. Sin embargo, en ambos universos encontramos relaciones directas del personaje con lo musical, especialmente en el Mampato de Themo.

Al comienzo de la historia "Mampato y Rena en el siglo XL (Themo) ${ }^{63 "}$ se puede observar que el personaje tiene afiches en las paredes de su pieza que revelan sus preferencias musicales: Ángel Parra y The Beatles. Esto da cuenta que sus gustos se orientan hacia las músicas populares urbanas y específicamente hacia músicos que a fines de los 60 y comienzos de los 70 tenían difusión en los medios de comunicación masiva en Chile ${ }^{64}$. Pero además esto revela que Mampato aprecia tanto la música popular chilena como la

56 Vega Etcheverry 2018: 156. Félix es el nombre del hijo de Óskar, hoy artista visual que de hecho publicó algunas de sus primeras incursiones como dibujante en la revista.

57 Castillo 2018. Al mismo tiempo, Warnken (2015: 111) califica a Armstrong como un "adultoniño".

58 En Chile se llama "mampato" al caballo chilote de estatura pequeña, un poni. En aquel suplemento homónimo de El Mercurio aparecía un poni llamado Mampato (Lolas 2015: 19).

59 Complementando lo dicho en nota anterior, mientras Mampato, un niño de clase media viaja por tiempos y espacios gracias a su cinturón de tecnología extraterrestre, Mañungo de Guidú en Cabrochico es un niño campesino y viaja a otros lugares (pero no a otros tiempos) montado en su cóndor Clotildo.

60 Según Valle (2018: 79-80).

61 Originalmente el dibujo de Mampato recordaba mucho a sus modelos, Astérix y Dennis the Menace. Themo le otorgó una fisonomía más distintiva y definitiva, y con una estatura normal para su edad (Valle 2018: 80-81). Curiosamente, hasta el No 70 (19 de mayo, 1971) un dibujo del personaje con su apariencia original encabezaba los índices en la primera página de la revista, mientras en la historieta del interior ya se había impuesto su apariencia definitiva en las viñetas a partir de $\operatorname{los} \mathrm{N}^{\circ} 5$ y $\mathrm{N}^{\circ} 6$.

62 El Mampato de Óskar desconocería a Ogú y a Rena, en cambio conoce al duende Kolofón, tiene nuevas aventuras con Xsé y realiza otros viajes (Ortega 2018: 11-12). Según algunas fuentes, en la vida real Óskar y Themo se llevaban bastante bien y colaboraron en algunas historias del personaje, tanto para la revista como por mero disfrute (Vega Encina 2018: 8; Vega Etcheverry 2018: 156), pero según otras hubo tensiones entre ellos (Valle 2018: 91-93).

63 Publicada desde $\mathrm{N}^{\circ} 57$ (30 diciembre, 1970) y hasta $\mathrm{N}^{\circ} 68$ (5 de mayo, 1971). Los títulos de cada historia de Mampato varían según las distintas reediciones y referencias.

64 En "Mampato y los piratas" de Themo (historia que no debe confundirse con otra de Óskar, con el mismo título), que no alcanzó a publicarse en la revista, aparece un afiche de The Bee Gees en el cuarto del protagonista. 
extranjera. Y en su familia, su abuelo parece ser aficionado de Gardel, por un afiche que tiene de este cantante en su casa, según se aprecia en una de las viñetas de "Mampato en la Reconquista ${ }^{65 "}$.
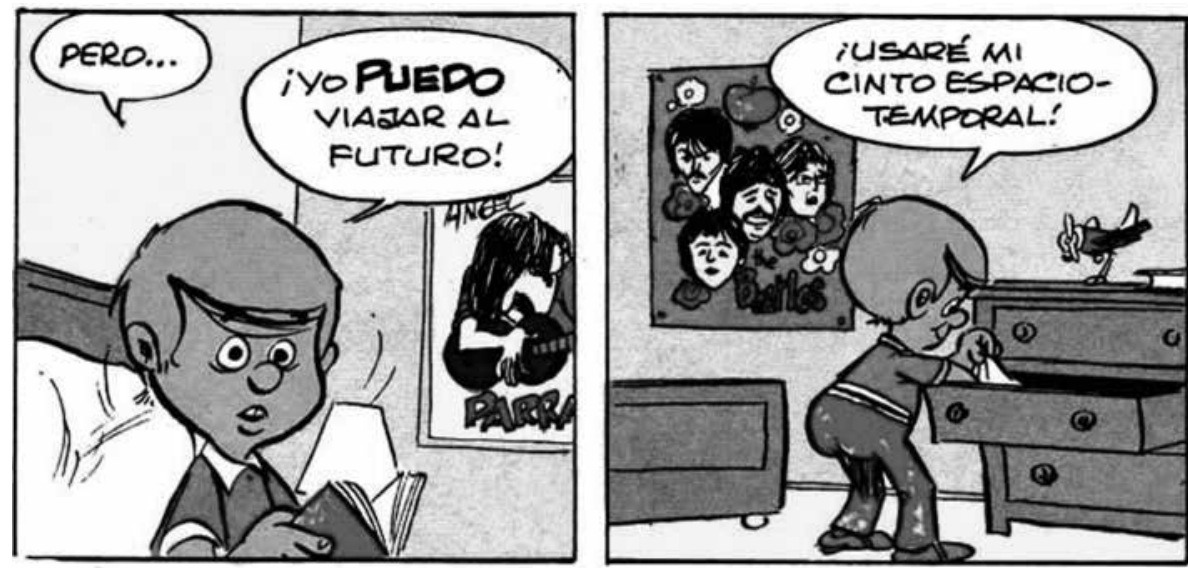

Imagen $\mathrm{N}^{\circ}$ 1: Afiches de Ángel Parra y The Beatles en el dormitorio de Mampato. Autor: Themo Lobos (Mampato No 57, 30 de diciembre, 1970: 10).

Mampato no solo escucha, sino practica música. El personaje canta "Somos los buenos muchachos 66 " en "Mampato en la playa (Óskar) 67 " y "Noche de paz" en "Dos ases del aire o El piloto loco (Themo) 68 ".
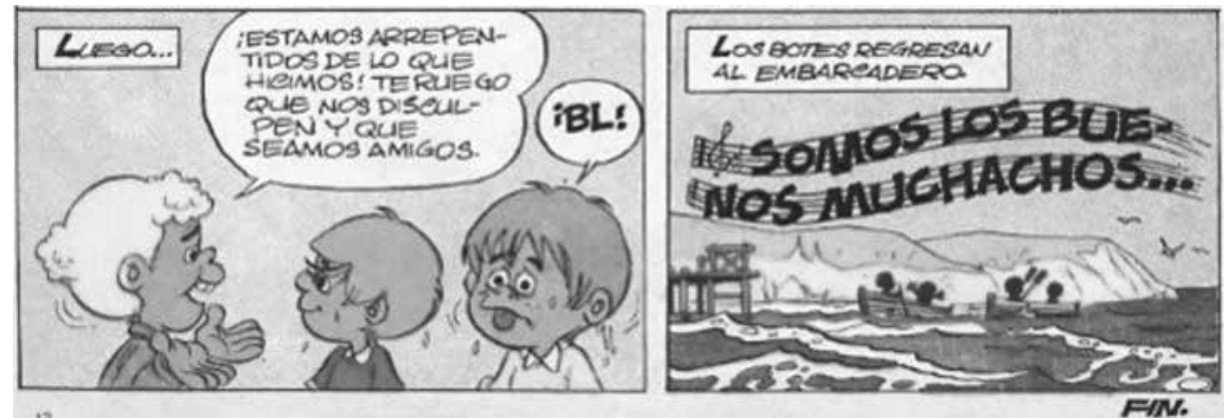

Imagen $\mathrm{N}^{\circ}$ 2: Mampato canta "Somos los buenos muchachos".

Autor: Óskar (Mampato $\mathrm{N}^{\circ}$ 213, 20 de febrero, 1974: 12).

65 Publicada desde $\mathrm{N}^{\circ} 129$ (5 de julio, 1972) hasta $\mathrm{N}^{\circ} 152$ (13 de diciembre, 1972).

66 "Somos los buenos muchachos" es una de las variantes en castellano de la canción tradicional "For He's a very good fellow", al igual que "Porque es un buen compañero" o "Es un muchacho excelente".

67 Historia unitaria de Óskar, publicada en $\mathrm{N}^{\circ} 213$ (20 de febrero, 1974): 9-12.

68 Publicada desde $\mathrm{N}^{\circ} 250$ (6 de noviembre, 1974) hasta $\mathrm{N}^{\circ} 257$ (23 de diciembre, 1974) y desde $\mathrm{N}^{\circ} 263$ (5 de febrero, 1975) hasta $\mathrm{N}^{\circ} 267$ (5 de marzo, 1975). 
Además en "Los suterones (Themo) ${ }^{69 "}$ vemos que puede improvisar versos. De paso, en esta última historia descubrimos que Rena canta maravillosamente (con versos de Lord Tennyson), lo que contribuye a la atracción creciente que el protagonista siente hacia ella. Mampato además maneja algunos instrumentos musicales como la guitarra (o instrumentos afines) al disfrazarse de músico ambulante en "Mampato en Bagdad (Themo) 70" y el tambor al enlistarse en el Ejército Libertador en "Mampato en la Reconquista (Themo)".
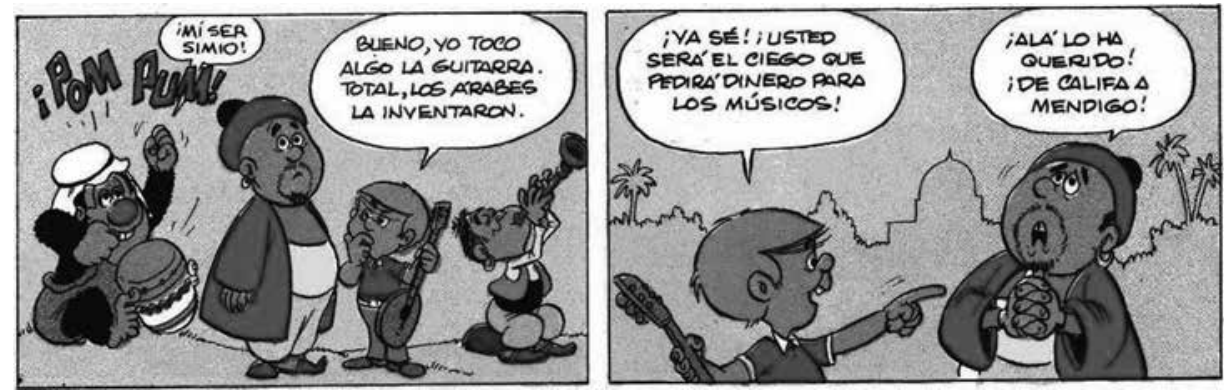

Imagen $\mathrm{N}^{\circ}$ 3: Mampato se disfraza de músico ambulante.

Autor: Themo Lobos (Mampato $\mathrm{N}^{\circ} 85,19$ de septiembre, 1971: 10).

Además aparecen prácticas musicales o cuasimusicales estereotípicas en el contexto de sus aventuras. Observamos toques de trompeta y el beethoveniano "ta-ta-ta-tan 71 " en boca tanto del piloto loco Denny en "El piloto loco" como de un soldado verdín en "Mampato contra los Verdines (Óskar)", el uso de tambores en la ceremonia de los Matabeques en "Mampato en África (Themo) ${ }^{72 " ~ y ~ l a ~ p r e s e n c i a ~ d e ~ u n ~ p i a n i s t a ~ e n ~ u n ~ s a l o ́ n ~ e n ~ " M a m p a t o ~}$ en el Lejano Oeste (Óskar/Themo) ${ }^{73 "}$ ". Asimismo apreciamos el canto ritual de un druida y de un escaldo en "Mampato y los vikingos (Themo) ${ }^{74}$ ", el canto festivo de un grupo de mosqueteros borrachos en "Mampato y los mosqueteros 75 " y una chingana en la época de la Reconquista en Chile (1814-1817) en la mencionada "Mampato en la Reconquista 76 ".

Hay que destacar un par de eventos musicales significativos en dos historias distintas, ambas escritas y dibujadas por Themo. En "Kilikilis y golagolas 77 ", la aventura donde viaja a la prehistoria y conoce a Ogú, Mampato indirectamente resulta ser el "padre de la música" al estimular la creatividad y exploración de los golagolas (seres humanos prehistóricos como Ogú $)^{78}$. Y en "Los suterones", aventura que transcurre en el siglo 40, Mampato y sus amigos encuentran un pueblo de poetas cantores. Uno de ellos, con ocasión de la celebración del

69 Publicada desde $\mathrm{N}^{\circ} 366$ (26 de enero, 1977) hasta $\mathrm{N}^{\circ} 378$ (20 de abril, 1977).

70 Publicada desde $\mathrm{N}^{\circ} 69$ (12 de mayo, 1971) hasta $\mathrm{N}^{\circ} 92$ (20 de octubre, 1971).

71 Onomatopeya del célebre motivo inicial de la Quinta Sinfonía de Beethoven, "el destino que llama a su puerta" asociado con situaciones de suspense.

72 Publicada desde $\mathrm{N}^{\circ} 105$ (19 de enero, 1972) hasta $\mathrm{N}^{\circ} 128$ (28 de junio, 1972).

73 Publicada desde $\mathrm{N}^{\circ} 206$ (2 de enero, 1974) hasta $\mathrm{N}^{\circ} 212$ (13 de febrero, 1974), y desde $\mathrm{N}^{\circ} 214$

(27 de febrero, 1974) hasta $\mathrm{N}^{\circ} 228$ (5 de junio, 1974).

74 Publicada desde $\mathrm{N}^{\circ} 229$ (12 de junio, 1974) hasta $\mathrm{N}^{\circ} 240$ (28 de agosto, 1974).

75 Publicada desde $\mathrm{N}^{\circ} 379$ (27 de abril, 1977) hasta $\mathrm{N}^{\circ} 399$ (14 de septiembre, 1977).

76 Podría agregarse el canto de piratas en un barco en "Mampato y los piratas" de Themo.

77 Publicada desde $\mathrm{N}^{\circ} 12$ (1969) hasta $\mathrm{N}^{\circ} 22$ (1969).

78 Rojas 2012b: 305. 
fin de la amenaza de los "suterones (topos gigantes mutantes)", entona décimas de Violeta Parra (de "Cuando llega el verano") ${ }^{79}$. Esto implica que para Themo la obra de Violeta (al igual que la de Lord Tennyson y el Martín Fierro de Hernández, cuyos versos también se citan en el relato) trascendería incluso hasta el siglo 40 y lo hace explícito en 1977, un año peligroso para recordarla públicamente en Chile.
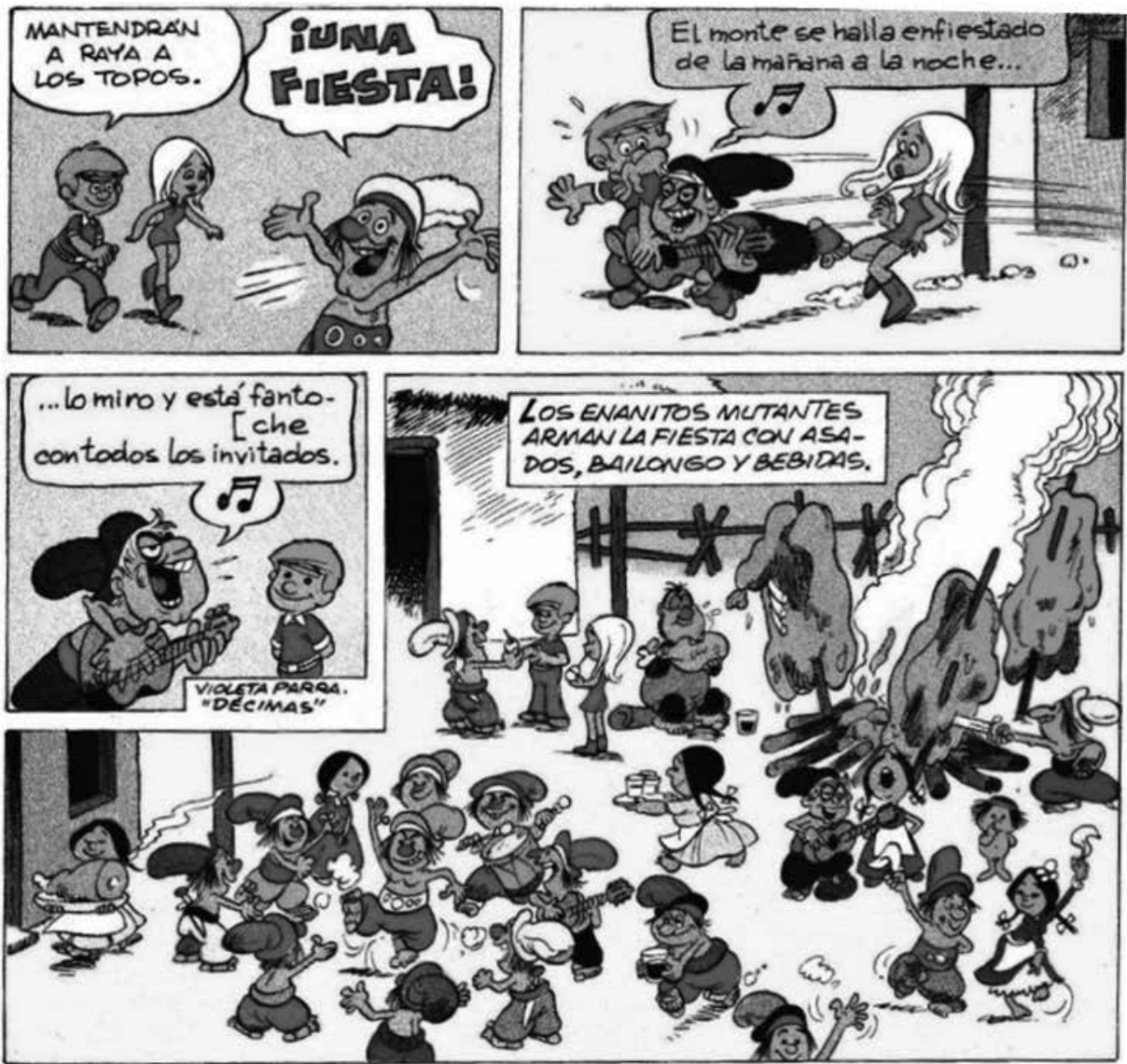

Imagen $\mathrm{N}^{\circ}$ 4: Un cantor entona décimas de Violeta Parra en el siglo 40.

Autor: Themo Lobos (Mampato $\mathrm{N}^{\circ}$ 378, 20 de abril, 1977: 10).

Esta red de representaciones musicales con las que se vincula a Mampato puede entenderse en correspondencia a los propósitos de la totalidad de la revista. Como expone Castillo ${ }^{80}$ :

79 Este personaje podría estar modelado en Miguel Arteche, subdirector de Mampato en esa época (Valle 2018: 83).

80 Castillo 2018. 
"Respecto de la totalidad de la revista, la historieta Mampato funciona como una proyección editorial a escala. Si en estricto rigor la historieta exige la creación de guiones y dibujos nuevos, ambos, en su perfil argumental e iconográfico, constituirán un sistema permanente de referencias a imágenes e historias ya disponibles en la cultura popular industrial, en la literatura de aventuras y ciencia ficción, en la historieta preexistente, en el cine y las series de televisión. La historieta Mampato representa figuradamente el mismo sistema de citas que caracteriza a la revista Mampato. En cada uno de sus gestos y de sus aventuras, el niño Mampato revisitará cada uno de los grandes mitos de origen de Occidente y los transformará en un modelo de interpretación del lugar mismo de la cultura chilena ante el espacio difuso y esquivo de la cultura occidental".

Desde esta perspectiva, la (re)presentación de músicas en las historias de Mampato constituye parte de ese "sistema de citas" que remite, en última instancia, al imaginario moderno de la cultura occidental. Pero no solo el canon musical académico o los estereotipos de las músicas étnicas y tradicionales se asoman en Mampato, sino también las modas de las músicas mediáticas y las huellas de la contingencia sociopolítica que afectaba a Chile en esos años. Y esto ocurre no solo en esta historieta, como veremos a continuación.

\section{LAS MÚSICAS EN OTRAS HISTORIETAS PUBLICADAS EN LA REVISTA MAMPATO}

Como se ha mencionado anteriormente, en la revista se publicaron otras historietas aparte de la principal, en formato unitario o de entregas en capítulos. La mayoría de ellas era de procedencia extranjera, entre ellas algunas de origen estadounidense que habían sido compradas por Editorial Lord Cochrane por su convenio previo con King Features. Sin embargo, la gran mayoría de las series extranjeras tenía origen franco-belga, extraídas principalmente de la revista Tintin. A ellas se sumaron importantes aportes de autores chilenos, especialmente bajo la dirección de Di Girolamo y de Pecchenino ${ }^{81}$. En todos estos relatos predominan tanto el género de aventuras con dibujo realístico como el género aventurero/humorístico con dibujo cómico y, al igual que en el caso de las historias de Mampato, encontramos en casos puntuales referencias a prácticas, repertorios o nociones acerca de diferentes músicas.

En las historietas de aventuras realísticas de autores chilenos, al final del relato "La tumba de hielo" de Los Cuatro de la Alborada de Germán Gabler (n. 1942) ${ }^{82}$, ambientada en el sur de Chile, se entona la canción "Somos los buenos muchachos", la misma que entona Mampato en "Mampato en la playa" de Óskar, a modo de celebración por el buen desenlace. En la historieta unitaria "Amarga Victoria" del chileno Manuel Cárdenas Arce (1939-2018) ${ }^{83}$, ambientada en la edad media, su protagonista, el príncipe Leopoldo de Aquitania, es acusado por su padre de refugiarse en la música y la poesía para eludir sus deberes, especialmente defender su feudo por la vía armada. Y en 1971 se publicó una adaptación a historieta del argumento de Rigoletto de Verdi, de autoría anónima pero posiblemente chilena ${ }^{84}$.

81 Hasson 2014: 77-84.

82 Publicada desde $\mathrm{N}^{\circ} 280$ (3 de junio, 1975) hasta $\mathrm{N}^{\circ} 284$ (1 de julio, 1975).

83 Publicada en $\mathrm{N}^{\circ} 181$ (4 de julio, 1973): 31-40.

$84 \mathrm{~N}^{\circ} 231$ (26 de junio, 1974): 33-39. 


\section{RTGOWEW}

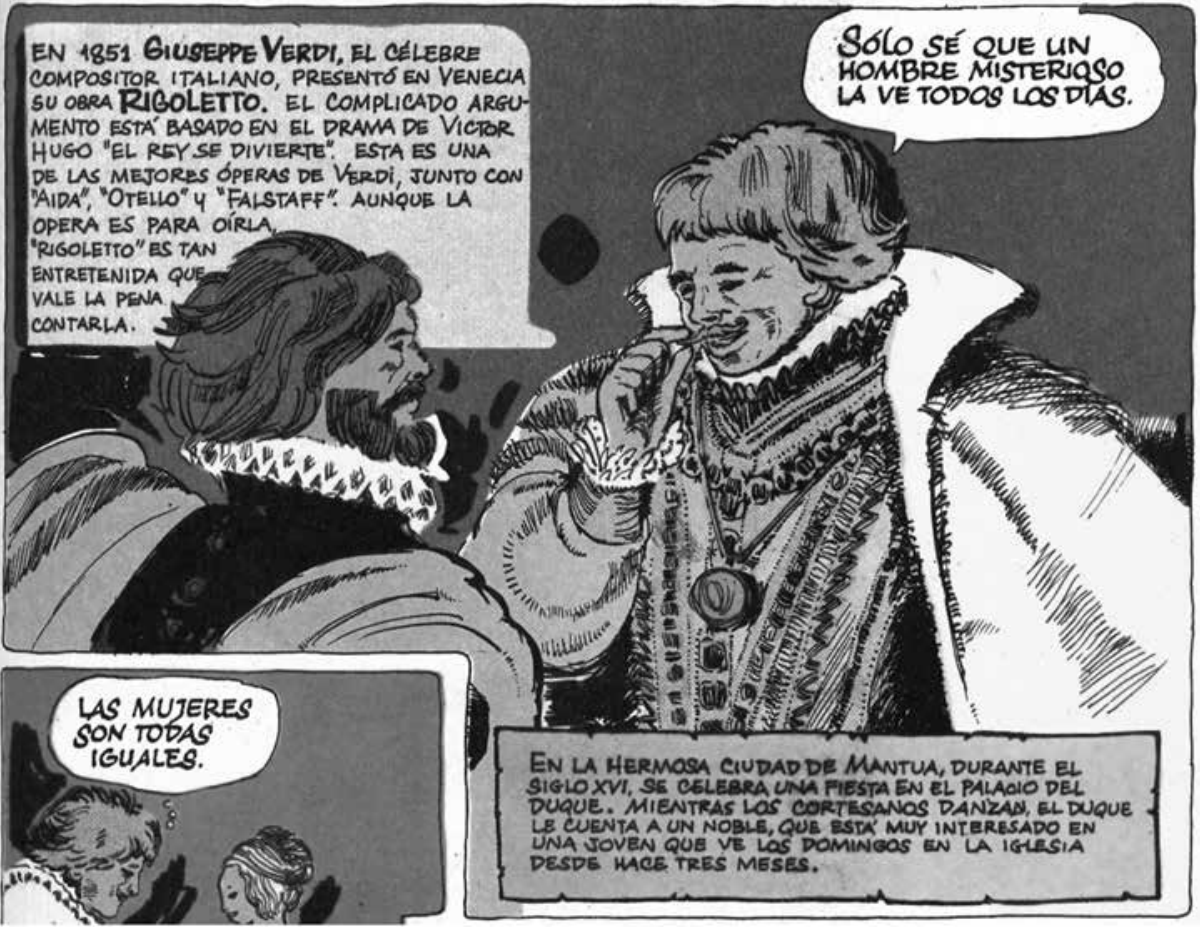

Imagen $\mathrm{N}^{\circ}$ 5: Viñetas iniciales de la adaptación de Rigoletto de Verdi.

Autor: anónimo (Mampato No 231, 26 de junio, 1974: 33).

Entre las historias de autores extranjeros, en el relato "La garra del tigre" de Howard Flynn ${ }^{85}$, el protagonista, un joven oficial de la marina británica de fines del siglo 18, se disfraza de mendigo organillero para entregar un mensaje ${ }^{86}$, dando cuenta así de prácticas musicales que se remontarían a ese contexto histórico. En una historia de Agentes Trueno $^{87}$, el superhéroe No-Man debe enfrentar a Vibraman, un peculiar supervillano ciego que resulta ser un experto en sonido y en armas acústicas. Y en el relato "Suspenso

85 Publicada desde $\mathrm{N}^{\circ} 18$ ([25 de junio], 1969) hasta $\mathrm{N}^{\circ} 24$ ([27 de septiembre], 1969). Autores: Yves Duval (1934-2009) y William van Custen "Vance" (1935-2018). Como regla general, en Mampato no se publicaban los nombres de los autores de las historietas extranjeras que se extraían de Tintin y otras revistas.

86 Mampato $\mathrm{N}^{\circ} 20$ ([23 de julio], 1969): 48.

87 T.H.U.N.D.E.R. Agents, de Tower Comics. Publicada desde $\mathrm{N}^{\circ} 1$ (30 de octubre, 1968) hasta $\mathrm{N}^{\circ} 3$ (27 de noviembre, 1968). 
en Indianápolis" de Michel Vaillant, se aprecia una banda desfilando con ocasión de una carrera automovilística ${ }^{88}$.

Ciertos estereotipos trasuntan en algunas de estas historias, como ocurre en la historieta de Mampato. Así, el personaje de Barney Jordan afirma que los enemigos que deberán enfrentar "no son niños de coro" al comienzo de "El general Satán" de Bernard Prince ${ }^{89}$, connotando que los niños o niñas coristas serían criaturas inofensivas o inocentes. En el caso de la serie Tung $a^{90}$, en dos relatos, "Tunga y el Dios del Fuego ${ }^{91}$ " y "Tunga y el pueblo de los árboles ${ }^{92 "}$, se representan tribus prehistóricas realizando sacrificios humanos donde intervienen el canto y la percusión. En la historia "Alerta en Borneo" de Los Franva ${ }^{93}$, una radio es calificada como "caja mágica" por los integrantes de una tribu no "civilizada94". Y al inicio del relato "Comando Caimán" de Bruno Brazi9", el protagonista se sorprende ante la popularidad de un concurso musical en TV.

Dentro de este rubro me detengo en tres historias más. La primera es "La ciudad petrificada" de Bruno Brazil ${ }^{96}$, donde el personaje de Gaucho aparece al comienzo cantando y tocando guitarra. Más adelante, gracias al canto el protagonista y sus compañeros evitan caer en un estado de shock inducido por una emisión de ultrasonido. El desenlace es casi un espejo del comienzo, con Gaucho nuevamente cantando y tocando guitarra.

Otra historia donde una canción juega un papel clave es "El príncipe de las dunas" de Corentin $^{97}$, donde gracias a una canción anónima que ha aprendido en su niñez, el personaje de Kim logra montar un caballo indócil que posteriormente resulta ser propiedad de un adolescente príncipe que debe recuperar su trono. Por último, en el relato "El secreto de Dan Cooper" de Dan Cooper ${ }^{98}$, aparece un recurso gráfico muy particular, donde el silbido con el que el protagonista llama a su perro es representado con una "partitura" encerrada en un globo de concepto ${ }^{99}$.

88 Autor: Jean Graton (n. 1923). Publicada desde $N^{\circ} 404$ (19 de octubre, 1977) hasta $N^{\circ} 418$ (25 de enero, 1978), esta historia quedó inconclusa debido al cierre de la revista.

89 Publicada desde $\mathrm{N}^{\circ} 150$ (29 de noviembre, 1972) hasta $\mathrm{N}^{\circ} 156$ (10 de enero, 1973). Autores: Greg (Michel Régnier, 1931-1999) y Hermann Huppen (n. 1938).

90 Autores: Jacques Acar (1937-1976) y Edouard Aidans (n. 1930).

91 Publicada desde $\mathrm{N}^{\circ} 72$ (2 de junio, 1971) hasta $\mathrm{N}^{\circ} 81$ (4 de agosto, 1971).

92 Publicada desde $\mathrm{N}^{\circ} 153$ hasta $\mathrm{N}^{\circ} 167$.

93 Publicada desde $\mathrm{N}^{\circ} 129$ hasta $\mathrm{N}^{\circ} 140$. Autores: Duval y Aidans.

94 Mampato $\mathrm{N}^{\circ} 133$ (2 de agosto, 1972): 45-46.

95 Publicada desde $\mathrm{N}^{\circ} 254$ (4 de diciembre, 1974) hasta $\mathrm{N}^{\circ} 262$ (29 de enero, 1975). Autores: "Louis Albert" (otro seudónimo de Michel Régnier o "Greg”) y Vance.

96 Publicada desde $\mathrm{N}^{\circ} 303$ (11 de noviembre, 1975) hasta $\mathrm{N}^{\circ} 313$ (20 de enero, 1976).

97 Publicada desde $\mathrm{N}^{\circ} 26$ ([15 de octubre], 1969) hasta $\mathrm{N}^{\circ} 39$ (22 de abril, 1970). Autores: Jean van Hamme (n. 1939) y Paul Cuvelier (1923-1978).

98 Publicada desde $N^{\circ} 126$ (14 de junio, 1972) hasta $\mathrm{N}^{\circ} 147$ (8 de noviembre, 1972). Autor: Albert Weinberg (1922-2011).

$99 \mathrm{~N}^{\mathrm{o}} 131$ (19 de julio, 1972): 33 y No 132 (26 de julio, 1972): 31. 


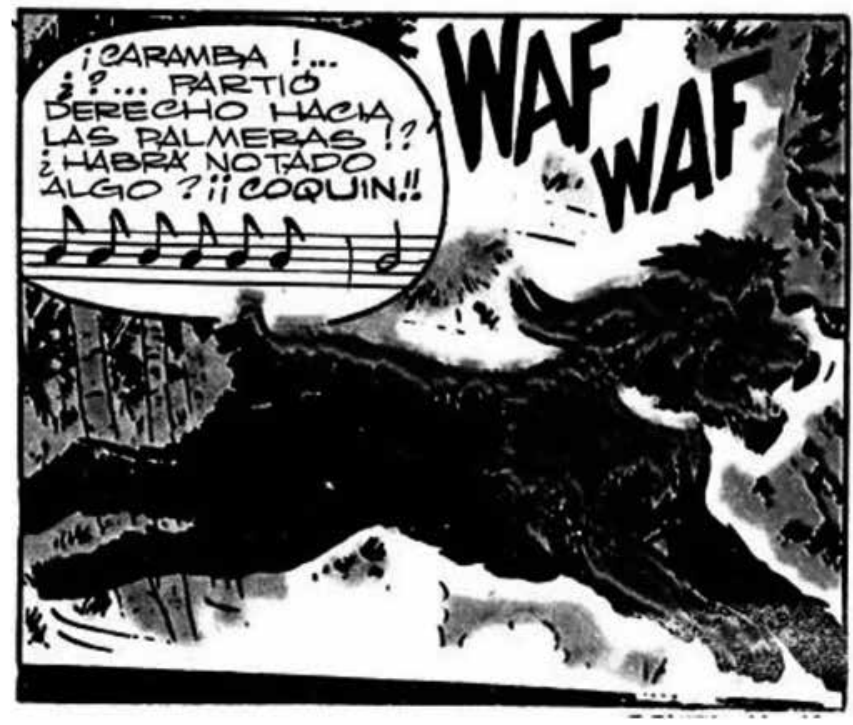

Imagen $\mathrm{N}^{\circ}$ 6: Viñeta de Dan Cooper.

Autor: Albert Weinberg (Mampato No 131, 19 de julio, 1972: 33).

En el rubro humorístico/aventurero de autores extranjeros, el personaje de Patatrac de Flordelis y Patatrac (Fleurdelys y Patacrac) ${ }^{100}$ intenta varias veces atraer a su amada Artemisa rindiéndole serenatas ${ }^{101}$, en otra historia trata de tocar el cuerno de los Alpes ${ }^{102}$, y canta al comienzo y al final de la aventura "Vivan las Vacaciones ${ }^{103 "}$ mientras navega junto con su camarada en el mar. En Korrigan ${ }^{104}$, el protagonista, un caballero medieval, se vincula con una familia de artistas ambulantes, entre ellos el juglar e instrumentista Drelindin. En la historia "El espejo de tres caras" de Olivier Rameau ${ }^{105}$, emergen el canto y baile al romperse un hechizo al final del relato.

A lo largo de un relato de Umpa-páa6, apreciamos un soldado prusiano que canturrea para darse valor al ser enviado a parlamentar con una tribu amerindia, el uso de instrumentos musicales en los preparativos de una batalla entre los ejércitos prusiano y francés, el toque de tambores de guerra en ceremonias amerindias y la entonación de la "Canción del Adiós" y de "A la claire fontaine" al finalizar el relato. Asimismo, al comienzo de una

100 Autores: Vicq (Antoine Raymond, 1936-1987) y Mazel (Luc Maezelle, n. 1931).

101 Historias unitarias publicadas en $\mathrm{N}^{\circ} 40$ (6 de mayo, 1970): 33-34; $\mathrm{N}^{\circ} 46$ (29 de julio, 1970): $36-37$ y N$^{\circ} 47$ (12 de agosto, 1970): 38-39.

$102 \mathrm{~N}^{\circ} 48$ (26 de agosto, 1970): 32-33.

$103 \mathrm{~N}^{\circ} 60$ (10 de febrero, 1971): 31-36.

104 Publicada desde $\mathrm{N}^{\circ} 262$ (29 de enero, 1975) hasta $\mathrm{N}^{\circ} 267$ (5 de marzo, 1975). Autores: Vicq y Franz (Franz Dappier, 1948-2003).

105 Publicada desde $\mathrm{N}^{\circ} 380$ (4 de mayo, 1977) hasta $\mathrm{N}^{\circ} 391$ (20 de julio, 1977). Autores: Greg y Dany (Daniel Henrotin, n. 1943).

106 Publicada desde $\mathrm{N}^{\circ} 268$ (12 de marzo, 1975) hasta $\mathrm{N}^{\circ} 275$ (30 de abril, 1975). Autores: Uderzo y Goscinny (los mismos de Astérix). 
historia de Astérix se presentan los personajes de su universo, entre ellos el inepto bardo Aseruranceturix, y más adelante los paisanos de Obélix le cantan "Cumpleaños feliz"107.

La serie Tippy Teen es protagonizada por una chica adolescente cuyo nombre, así como el de su mejor amiga, Go-Go West, alude a onomatopeyas de resonancias musicales ${ }^{108}$. De hecho Go-Go es cantante folk, aunque en Mampato no se publicaron historias que la presenten así, pero en el relato "Corazones y flores" afirma que si tuviera un violín tocaría la canción homónima ("Hearts and Flowers") que da nombre a esa historia109.

En las tiras cómicas de La tribu terrible (Redeye) de Gordon Bess (1929-1989) el personaje de Pluma de Huevo (Tanglefoot) fabrica silbatos, se ilusiona con el juego de la concha marina y usa cuerdas de guitarra para fabricar $\operatorname{arcos}^{110}$, mientras el niño Cuarto de Pluma (Pokey) se frustra por la aparente inutilidad de una flauta "ultrasónica111". Asimismo, en Max el Explorador se hallan algunas tiras de contenido musical ${ }^{112}$, así como en viñetas de humor gráfico de los chilenos Néstor Espinoza ${ }^{113}$ y Juan Cano Alcayaga (n. 1943) ${ }^{114}$ u otras sin firma de autor ${ }^{115}$.

Entre las historietas de autores chilenos se destacan aquellas protagonizadas por Nick Obre, otro personaje creado por Themo ${ }^{116}$. Se trata de un detective privado que medita y ordena sus pensamientos tocando guitarra eléctrica en su casa, lo que es un guiño paródico a Sherlock Holmes, célebre personaje que realiza lo mismo con su violín. Por otra parte, la participación de bandas en las celebraciones patrióticas y cívicas aparece insinuada en la inauguración del monumento a Pedro de Zañartiaga, fundador de la ficticia ciudad de Piduquén, en una historia protagonizada por Máximo Chambónez, otro personaje de Themo ${ }^{117}$.

Relatos que resultan muy significativos son aquellos protagonizados por la niña Chepita, personaje creado por Guidú (Freddy Guillermo Durán, n. 1946). En uno de ellos presta auxilio a unos diminutos personajes alados llamados "Luchín" y "Negro José" para enfrentar a unas larvas malvadas. El canto juega un papel importante en la resistencia y victoria final118. Recordemos que "Luchín" es el nombre de una de las canciones más recordadas del cantautor Víctor Jara, asesinado a los pocos días del golpe militar en Chile, mientras el Negro José es el protagonista de "Candombe para José”, canción original del argentino

107 Publicada desde $N^{\circ} 417$ (18 de enero, 1978) hasta $N^{\circ} 418$ (25 de enero, 1978). Esta historia, titulada "Obélix y Compañía", quedó inconclusa debido al cierre de la revista.

108 "Tippy Teen" nos remite a la canción "Tipi-tipi-tin” de María Grever (1885-1951), difundida en varias versiones por numerosos intérpretes., mientras "Go-Go West" nos remite al club nocturno Whisky a Go Go en West Hollywood, considerado como una de las primeras discotecas en Estados Unidos y lugar de inicio en la trayectoria de varios músicos. Autor: Sam Schwartz (1920-1997).

$109 \mathrm{~N}^{\mathrm{o}} 3$ (27 de noviembre, 1968): 34. La canción "Heart and flowers" fue compuesta por Theodore Moses Tobani (1855-1933), con letra de Mary D. Brine, y publicada en 1893. Muy usada para acompañar situaciones melodramáticas en filmes mudos, posteriormente ha sido asociada a las parodias de esas situaciones en filmes sonoros y espectáculos teatrales.

$110 \mathrm{~N}^{\mathrm{o}} 82$ (11 de agosto, 1971): 32; $\mathrm{N}^{\circ} 99$ (8 de diciembre, 1971): 37; $\mathrm{N}^{\circ} 198$ (7 de noviembre, 1973): 40; $\mathrm{N}^{\circ} 224$ (8 de mayo, 1974): 54; $\mathrm{N}^{\circ} 203$ (12 de diciembre, 1973): 23.

$111 \mathrm{~N}^{\circ} 72$ (2 de junio, 1971): 21.

$112 \mathrm{~N}^{\circ} 84$ (25 de agosto, 1971): 40. Autor: Guy Bara (Guy Willems, 1923-2003).

$113 \mathrm{~N}^{\mathrm{o}} 41$ (20 de mayo, 1970): 55; $\mathrm{N}^{\circ} 55$ (2 de diciembre, 1970): 55; $\mathrm{N}^{\circ} 66$ (21 de abril, 1971): 55; $\mathrm{N}^{\circ} 71$ (26 de mayo, 1971): 55; $\mathrm{N}^{\circ} 73$ (9 de junio, 1971): 55; $\mathrm{N}^{\circ} 95$ (10 de noviembre, 1971): 55; $\mathrm{N}^{\circ} 97$ (24 de noviembre, 1971): 55; No 111 ([1 de marzo], 1972): 55; $\mathrm{N}^{\circ} 124$ (31 de mayo, 1972): 55.

$114 \mathrm{~N}^{\circ} 164$ (7 de marzo, 1973): 53; No 205 (26 de diciembre, 1973): 53; No 287 (22 de julio, 1975):

53; $\mathrm{N}^{\mathrm{o}} 306$ (2 de diciembre, 1975): 50.

$115 \mathrm{~N}^{\mathrm{0}} 410$ (30 de noviembre, 1977): 45.

116 Publicadas en $\mathrm{N}^{\circ} 66$ (21 de abril, 1971); $\mathrm{N}^{\mathrm{o}} 70$ (9 de mayo, 1971) al $\mathrm{N}^{\mathrm{o}} 77$ (7 de julio, 1971); $\mathrm{N}^{\circ} 84$ (25 de agosto, 1971) al $\mathrm{N}^{\circ} 88$ (22 de septiembre, 1971) y $\mathrm{N}^{\circ} 173$ (9 de mayo, 1973).

$117 \mathrm{~N}^{\mathrm{o}} 6$ ([8 de enero], 1969): 25.

118 Publicada entre $\mathrm{N}^{\mathrm{o}} 364$ (12 de enero, 1977): 32-35 y No 365 (19 de enero, 1977): 41-44. 
Roberto Ternán (Roberto Juan Ternavasio, n. 1943) y popularizada en Chile por el grupo Illapu, con una connotación muy particular:

"Durante la dictadura militar 'Candombe para José' tomó una nueva significación que la hizo constituirse en un himno al interior de los campos de concentración. Representaba tanto la alegría como la tristeza: los presos políticos entonaban esta canción cada vez que llegaba un nuevo preso, o alguno salía en libertad, o bien, para apoyar a alguien que era torturado o recibía un castigo. Los presos cambiaron el texto original de ‘Arriba Negro José' por ‘Ánimo Negro José', regalando un abrazo en una canción"119”.

Estos personajes reaparecen en un relato posterior, donde se cita explícitamente parte del "Candombe para José" al ser cantado por Chumingo, uno de los personajes ${ }^{120}$. Y en otro relato, Chepita y Chumingo van al altiplano y allí un personaje llamado Cucumani, de origen aymara, les da una charla acerca de la quena, instrumento que toca, y los invita a fabricar quenas y zampoñas (instrumentos proscritos en los inicios de la dictadura) ${ }^{121}$.
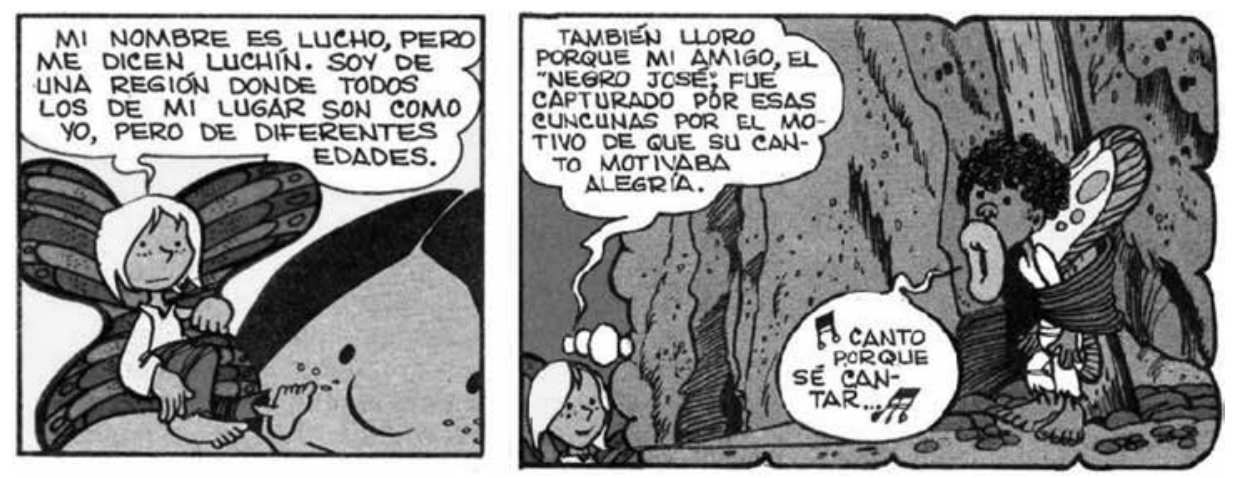

Imagen $\mathrm{N}^{\circ}$ 7: Luchín y el Negro José en Chepita.

Autor: Guidú (Mampato $\mathrm{N}^{\circ}$ 364, 12 de enero, 1977: 32).

Guidú era amigo de Víctor Jara y su compromiso con los ideales de la UP es claro al considerar que fue uno de los artistas del equipo de Cabrochico y creador de Mañungo, el niño "rival" de Mampato durante esa época. Con estos antecedentes y debido al contexto histórico, la publicación de estas historias en ese año (1977) resulta particularmente relevante ${ }^{122}$.

\section{BIOGRAFÍAS DE MÚSICOS Y CUENTOS MUSICALES}

La revista tenía una sección de una a dos páginas destinada a la biografía de algún personaje histórico destacado de diferentes áreas o épocas. En esta sección se publicaron biografías

119 www.tiesosperocumbiancheros.cl/?p=77 [consulta: 9 de noviembre, 2018]; González y Varas 2003: 104.

120 Publicada entre $\mathrm{N}^{\circ} 371$ (2 de marzo, 1977): 41-44 y No 372 (9 de marzo, 1977): 41-44.

121 No 367 (2 de febrero, 1977): 41-44; González y Varas 2003: 105.

122 Entrevista a Guidú en https:/ /acciondirectachile.blogspot.com/2015/07/guidu-habla-de-larevista-cabrochico.html [consulta: 9 de noviembre, 2018]. En ella el dibujante relata su amistad con Jara y su llegada a Mampato por invitación de Themo Lobos. 
de compositores europeos: Palestrina ${ }^{123}$, Bach ${ }^{124}$, Vivaldi ${ }^{125}$, Mozart ${ }^{126}$, Beethoven ${ }^{127}$, Schubert ${ }^{128}$, Mendelssohn ${ }^{129}$, Wagner ${ }^{130}$, Verdi ${ }^{131}$, Debussy ${ }^{132}$, Bartók ${ }^{133}$ y Manuel de Falla ${ }^{134}$. En el caso de Mozart y Beethoven, dos veces se publicó su biografía, más ampliada en la segunda ocasión. Se trata de biografías de divulgación didáctica, obviamente sin ninguna pretensión de profundización musicológica, con retratos dibujados a menudo por Armstrong ${ }^{135}$.

Retratos con breves frases biográficas de estos compositores aparecieron en las portadas interiores del $\mathrm{N}^{\circ} 40$ de 1970. Además, imágenes de algunos de ellos, no exactamente las mismas que aparecieron en las biografías, se usaron como parte integrante de los "Mampatogramas" que se publicaban en la revista. Como curiosidad, menciono que en un artículo pertinente a grafología publicado en $1972^{136}$, se presenta la escritura manuscrita de Vivaldi, Bach, Mozart y Beethoven entre otros personajes ilustres.

Aparte de estas biografías, en la revista se publicaron dos "biografías de piezas musicales", concretamente "Noche de paz ${ }^{137 " ~ y ~ " L a ~ M a r s e l l e s a 138 ", ~ e s t a ~ u ́ l t i m a ~ c o n ~ u n ~ e x t r a c t o ~ d e ~ l a ~}$ melodía en partitura. Yjunto con este tipo de relatos habría que mencionar algunos cuentos de temática musical como "El trovador del rey y su hermano" de Óscar Garaycochea139, "Filiberto Mardones" de Isabel Allende ${ }^{140}$ "Los números cantan y bailan" de la niña María Loreto Mery Castro ${ }^{141}$ y "La sonata del diablo" de Alfonso Calderón (1930-2009) ${ }^{142}$.

\section{ARTÍCULOS ESPECIALES ACERCA DE MÚSICA Y SONIDO}

Entre los números 223 y 243 de 1974 de Mampato, cada dos números aproximadamente, se publicó una serie de nueve artículos divulgativos concernientes a historia de la música académica occidental, firmados por Elga Pérez Laborde. Se trataba de una estudiante de periodismo en la Universidad de Chile y que tenía estudios en pedagogía en educación. Se graduó en 1977 y posteriormente prosiguió estudios de posgrado en la Universidad de Brasilia, donde obtuvo un doctorado en literatura en 2004. Ha desarrollado una carrera académica y además como intérprete y gestora de conciertos poético-musicales de autores latinoamericanos. Por tanto, estos artículos relacionados con la historia de la música

$123 \mathrm{~N}^{\mathrm{o}} 196$ (24 de octubre, 1973): 16.

$124 \mathrm{~N}^{\mathrm{o}} 20$ ([23 de julio], 1969): 16.

$125 \mathrm{~N}^{\circ} 97$ (24 de noviembre, 1971): 16.

$126 \mathrm{~N}^{\circ} 4$ (11 de diciembre, 1968): 16; No 376 (6 de abril, 1977): 32-35.

$127 \mathrm{~N}^{\mathrm{o}} 9$ ([19 de febrero], 1969): 16; N 396 (24 de agosto, 1977): 33-37.

$128 \mathrm{~N}^{\mathrm{o}} 107$ (2 de febrero, 1972): 16-17.

$129 \mathrm{~N}^{\mathrm{o}} 240$ (28 de agosto, 1974): 52.

$130 \mathrm{~N}^{\mathrm{o}} 155$ (3 de enero, 1973): 16.

$131 \mathrm{~N}^{\circ} 173$ (9 de mayo, 1973): 16.

$132 \mathrm{~N}^{\mathrm{o}} 149$ (22 de noviembre, 1972): 16.

$133 \mathrm{~N}^{\mathrm{o}} 352$ (20 de octubre, 1976): 18-21.

$134 \mathrm{~N}^{\mathrm{o}} 228$ (5 de junio, 1974): 16.

135 Armstrong 2015: 9.

$136 \mathrm{~N}^{\circ} 124$ (31 de mayo, 1972): 20-25.

$137 \mathrm{~N}^{\circ} 308$ (16 de diciembre, 1975):18-21.

$138 \mathrm{~N}^{\circ} 338$ (14 de julio, 1976): 21.

$139 \mathrm{~N}^{\mathrm{o}} 220$ (10 de abril, 1974): 4-8. Garaycochea es un destacado guionista de cine y académico argentino, avecindado en Chile.

$140 \mathrm{~N}^{\mathrm{o}} 240$ (28 de agosto, 1974): 38-40.

$141 \mathrm{~N}^{\circ} 252$ (20 de noviembre, 1974): 16. Mery estudió la carrera de geografía y se ha desempeñado en cargos públicos (http:/ / fedefruta.cl/maria-loreto-mery-es-la-nueva-secretaria-ejecutiva-de-la-cnr/ [acceso: 12 de noviembre de 2018]).

$142 \mathrm{~N}^{\circ} 312$ (13 de enero, 1976): 14-15. 
constituyen una primera incursión en un ámbito en el que ha continuado investigando y creando en los años posteriores a su participación en la revista ${ }^{143}$.

En artículos acerca de la historia del teatro aparecieron capítulos dedicados a la ópera ${ }^{144}$, en otro en torno al cine se abordó la comedia musical ${ }^{145}$ y en un texto de Ramón Lira titulado "Personajes típicos del antiguo Santiago" se menciona a los pianistas de teatro ${ }^{146}$. En 1969 se publicó en una página una historia ilustrada del gramófono y de la grabación fonográfica ${ }^{147}$. Dentro del ámbito de la música académica, en $1970^{148}$ se publicó un artículo acerca de los instrumentos musicales de la orquesta sinfónica. En $1973^{149}$ apareció un texto dedicado al jazz, sin firma, donde se abordan las raíces de este complejo genérico (spirituals, blues) y algunas referencias a los estilos Dixieland, New Orleans e inicios del Swing. Es decir, sin considerar las diferentes corrientes del jazz moderno desarrolladas a partir del Bebop ni los estilos posteriores.

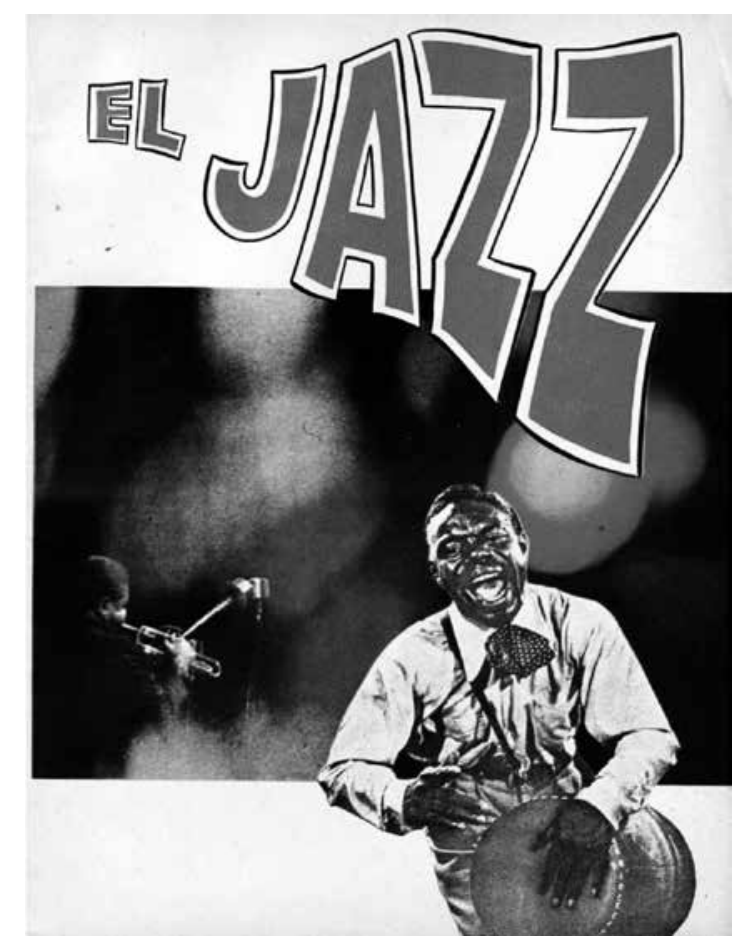

Imagen $\mathrm{N}^{\circ}$ 8: Página inicial de artículo acerca del jazz (Mampato $\mathrm{N}^{\circ} 173$, 9 de mayo, 1973: 17).

143 Un texto relativamente reciente de Pérez Laborde es "Los códigos de la modernidad en los textos poético-musicales de Violeta Parra y Chico Buarque”, Contextos, 20, 2008, pp. 139-146.

$144 \mathrm{~N}^{\circ} 290$ (12 de agosto, 1975): 8; No 316 (10 de febrero, 1976): 8.

$145 \mathrm{~N}^{\circ} 297$ (30 de septiembre, 1975): 8.

$146 \mathrm{~N}^{\circ} 222$ (24 de abril, 1974): 18-21.

$147 \mathrm{~N}^{\mathrm{o}} 25$ ([1 de octubre, 1969): 13.

$148 \mathrm{~N}^{\mathrm{o}} 40$ (6 de mayo, 1970): 20-23.

$149 \mathrm{~N}^{\circ} 173$ (9 de mayo, 1973): 17-21. 
También en 1973 se publicó una serie de tres artículos acerca de los instrumentos folclóricos chilenos ${ }^{150}$. En $1976^{151}$, en la sección "Minienciclopedia temática", apareció una serie de cuatro artículos en torno al sonido, con la firma de "EST (el periodista Enrique Santiz Téllez)". Y en 1977152 se publicaron siete fichas de instrumentos musicales tradicionales de Chile bajo el rubro "Artesanía y folklore". Con este último tipo de material, la revista cumplía su orientación didáctica y, de paso, contribuía a difundir el conocimiento acerca de la cultura musical tradicional.

\section{ENTREVISTAS Y REPORTAJES: PUERTAS ADENTRO, NUESTRA PÁGINA Y OTRAS SECCIONES}

En la sección "Puertas Adentro", como se ha mencionado, se realizaron reportajes a niños y jóvenes de diferentes clases sociales, a cargo de la periodista Cecilia Eyzaguirre. Entre ellos, niños y jóvenes estudiantes de arte o de música que posteriormente llegarían a ser destacados o destacadas profesionales. Así, tanto en "Puertas Adentro" como otras secciones como "Nuestra Página ${ }^{153}$ " encontramos entrevistas a Vivian Wurman (hoy pianista y rectora del Instituto Escuela Moderna de Música) ${ }^{154}$, los hermanos Bitrán Goren (hoy destacados músicos e investigadores) ${ }^{155}$, Carlos Dourthé (hoy violoncelista) ${ }^{156}$, los hermanos Aliaga Lewis (hoy varios de ellos artistas) ${ }^{157}$, Barroco Andino Niños (con los hermanos Ernesto y Rodrigo Pérez, ambos músicos vigentes) ${ }^{158}$ y Sebastián Santa María Pérez (1959-1996, cantautor y productor musical, prematuramente fallecido) ${ }^{159}$. Pero también encontramos referencia a niños y niñas cuya trayectoria posterior en la música desconocemos: el Coro Niño y Patria ${ }^{160}$, Los Parralitos ${ }^{161}$, Cherie Grace ${ }^{162}$, Raulito Gálvez Canales ${ }^{163}$, el venezolano Gregory O’Brien ${ }^{164}$ o Los Patitas Negras ${ }^{165}$, así como otros que derivarían hacia otros ámbitos como Claudio Troncoso Repetto (hoy abogado y académico) ${ }^{166}$.

$150 \mathrm{~N}^{\mathrm{o}} 200$ (21 de noviembre, 1973): 50-51, No 201 (28 de noviembre, 1973): 50-51, No 202 (5 de diciembre, 1973): 50-51.

151 Serie publicada entre Mampato $\mathrm{N}^{\circ} 353$ (27 de octubre, 1976) y No 356 (17 de noviembre, 1976).

152 Fichas publicadas desde Mampato $\mathrm{N}^{\circ} 388$ (29 de junio, 1977) hasta $\mathrm{N}^{\circ} 394$ (24 de agosto, 1977).

153 Esta sección debuta en Mampato $\mathrm{N}^{\circ} 110$ (23 de febrero, 1972): 53.

$154 \mathrm{~N}^{\circ} 207$ (9 de enero, 1974): 42.

$155 \mathrm{~N}^{\mathrm{o}} 181$ (4 de julio, 1973): 42-43. Los hermanos Saúl, Arón y Álvaro Bitrán son fundadores e integrantes del Cuarteto Latinoamericano, mientras Yael Bitrán es musicóloga.

$156 \mathrm{~N}^{\mathrm{o}} 322$ (23 de marzo, 1976): 45.

$157 \mathrm{~N}^{\mathrm{o}} 132$ (26 de julio, 1972): 42-43. Raúl Aliaga Lewis, percusionista, es actualmente integrante del grupo Congreso, mientras Constanza y Andrés Aliaga Lewis son artistas visuales.

$158 \mathrm{~N}^{\circ} 291$ (19 de agosto, 1975): 8. Ambos hermanos fundaron el grupo Napalé.

$159 \mathrm{~N}^{\mathrm{o}} 148$ (15 de noviembre, 1972): 42-43.

$160 \mathrm{~N}^{\mathrm{o}} 135$ (16 de agosto, 1972): 42-43.

$161 \mathrm{~N}^{\circ} 155$ (3 de enero, 1973): 42-43.

$162 \mathrm{~N}^{\circ} 159$ (31 de enero, 1973) 42-43.

$163 \mathrm{~N}^{\circ} 162$ (21 de febrero, 1973) 42-43.

$164 \mathrm{~N}^{\circ} 216$ (13 de marzo, 1974): 42-43.

$165 \mathrm{~N}^{\circ} 305$ (25 de noviembre, 1975): 48-49.

$166 \mathrm{~N}^{\mathrm{o}} 219$ (3 de abril, 1974): 42-43. 


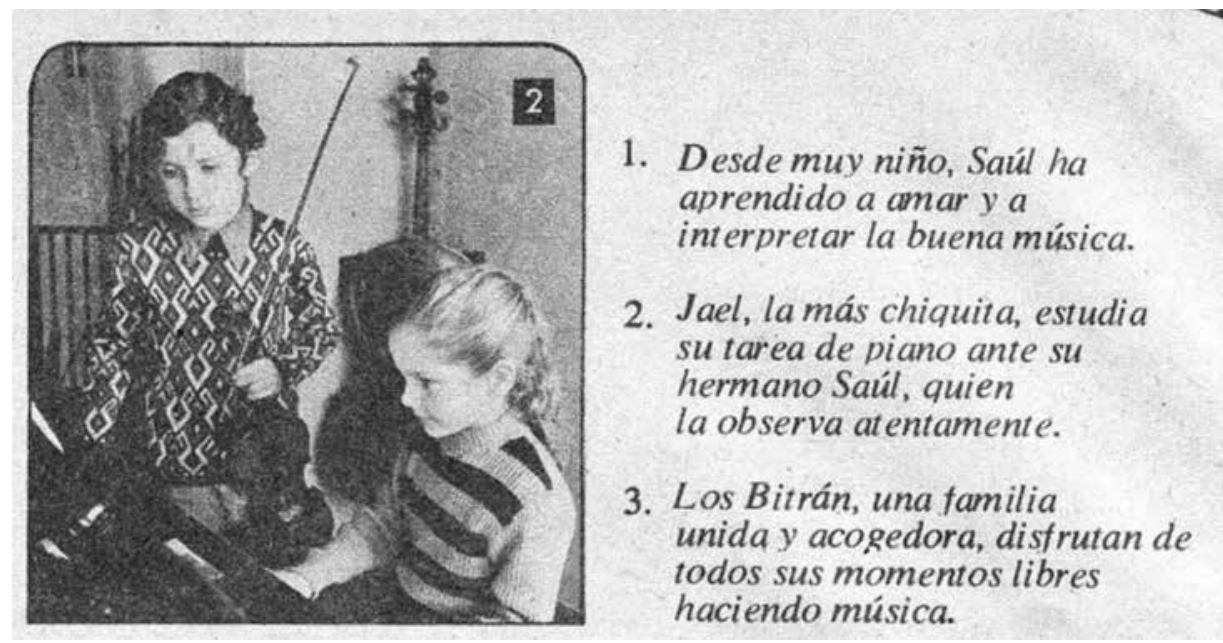

Imagen $\mathrm{N}^{\circ}$ 9: Los hermanos Saúl y Yael Bitrán Goren

(Mampato $\mathrm{N}^{\circ} 181,4$ de julio, 1973: 43).

En otras secciones se mencionan a otros niños y jóvenes que posteriormente se convertirían en poetas, músicos e incluso investigadores. En "Nuestra Página" aparecieron en 1973 una carta y poema de un joven estudiante interesado en contactarse con otros aficionados a la poesía llamado Eduardo Peralta (hoy cantautor y payador) ${ }^{167}$, así como en 1972 el dibujo de un adolescente Rodrigo Durán Carrasco (hoy violoncelista y compositor vinculado a proyectos como Entrama) ${ }^{168}$. En 1976 se anuncian los resultados de un concurso de dibujo organizado por un estudiante de octavo básico en el colegio Alonso de Ercilla, de nombre Ronald Harris (hoy arquitecto y académico universitario) ${ }^{169}$. Por otra parte, en la sección de hobbies se presentó en 1969 a un niño que dibujaba historietas llamado Cristán Warnken Lihn (hoy poeta, académico y comunicador) ${ }^{170}$ y en 1971 a otro que era coleccionista de soldaditos de plomo identificado como Claudio Rolle Cruz (hoy historiador y académico universitario) ${ }^{171}$.

Aparte de estas entrevistas a personas específicas, se publicaron además reportajes enfocados en Chile o en el extranjero donde las referencias o prácticas musicales se hacen presentes. Entre los primeros mencionemos un reportaje de Carmen Ossa acerca de la fiesta de La Tirana ${ }^{172}$ y otro acerca de la fiesta de Andacollo ${ }^{173}$. Y entre los segundos, dos textos en torno a los encantadores de serpientes en la India ${ }^{174}$, un reportaje acerca de Austria

$167 \mathrm{~N}^{\circ} 170$ (18 de abril, 1973): 55.

$168 \mathrm{~N}^{\mathrm{o}} 124$ (31 de mayo, 1972): 53.

$169 \mathrm{~N}^{\mathrm{o}} 348$ (22 de septiembre, 1976).

$170 \mathrm{~N}^{\mathrm{o}} 21$ (6 de agosto, 1969).

$171 \mathrm{~N}^{\circ} 73$ (9 de junio, 1971): 44.

$172 \mathrm{~N}^{\circ} 183$ (18 de julio, 1973): 26-30.

173 No 206 (2 de enero, 1974): 18-21. En el mismo número en "Puertas Adentro" (pp. 41-42) se presenta a dos niñas promeseras que bailan en esta fiesta.

$174 \mathrm{~N}^{\mathrm{o}} 122$ (17 de mayo, 1972): 49-51; No 167 (28 de marzo, 1973): 50-51. 
con notas respecto de compositores como Gluck y Mozart ${ }^{175}$, y otro acerca de la historia de la Ópera de Sidney ${ }^{176}$.

\section{GALERÍA DE ESTRELLAS}

En los primeros 127 números de Mampato y posteriormente en forma más esporádica, retomando una regularidad relativa desde el $\mathrm{N}^{\circ} 377$ hasta el último número de la revista, aparece una sección denominada inicialmente "Cine, discos, TV" y posteriormente, a partir del № 27 de 1969 (número aniversario de la revista), "Galería de Estrellas". Esta sección presentaba fotografías de deportistas, actores y actrices, cantantes y músicos, tanto de Chile como del extranjero.

En la sección de correo de Mampato se publicaron cartas tanto en contra ${ }^{177}$ como a favor de esta sección, a veces incluso con solicitudes de fotografías de "estrellas" específicas ${ }^{178}$. Así, en un mismo número podemos encontrar a Palmenia Pizarro y a The Beach Boys ${ }^{179}$, Barry Ryan y Joan Manuel Serrat ${ }^{180}$, Víctor Jara y Godfrey Stevens ${ }^{181}$, Los Huasos Quincheros y Raphael ${ }^{182}$, Quilapayún ${ }^{183}$, el Chavo del Ocho y el Chapulín Colorado (personajes del mexicano Chespirito) ${ }^{184}$.
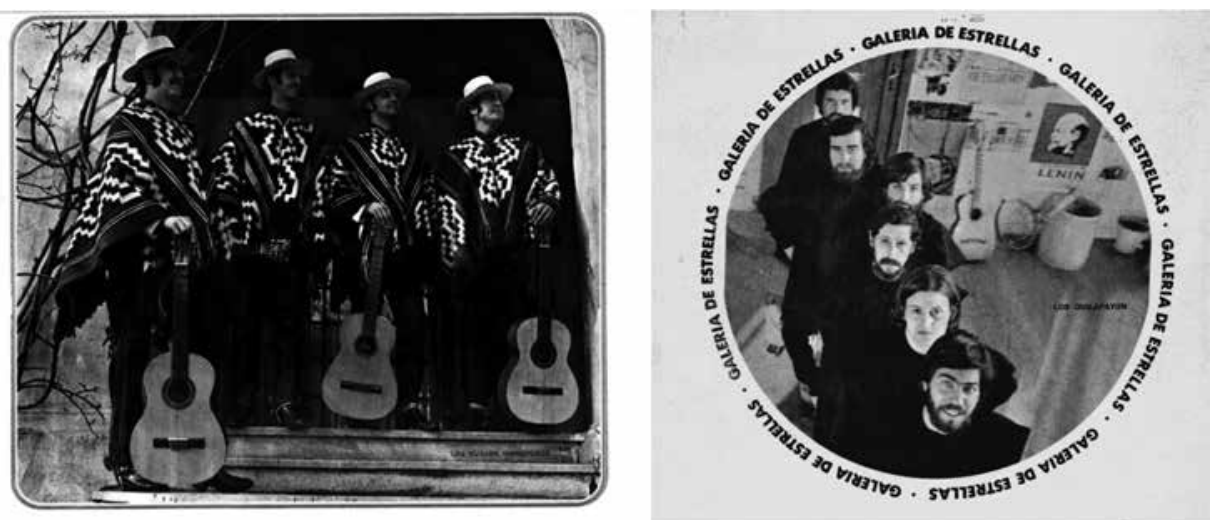

Imagen $\mathrm{N}^{\circ} 10$ y N $\mathrm{N}^{\circ} 11$ : Los Huasos Quincheros y Quilapayún en "Galería de Estrellas" (Mampato $\mathrm{N}^{\circ}$ 89, 29 de septiembre, 1971: 53; $\mathrm{N}^{\circ}$ 98, 1 de diciembre, 1971: 54).

$175 \mathrm{~N}^{\mathrm{o}} 397$ (31 de agosto, 1977): 36-37.

$176 \mathrm{~N}^{\circ} 370$ (23 de febrero, 1977): 17-20.

$177 \mathrm{~N}^{\mathrm{o}} 26$ ([15 de octubre], 1969): 3.

$178 \mathrm{~N}^{\mathrm{o}} 4$ (11 de diciembre, 1968): 3; $\mathrm{N}^{\mathrm{o}} 10$ ([5 de marzo], 1969): 3; $\mathrm{N}^{\mathrm{o}} 36$ (11 de marzo, 1970): 3.

$179 \mathrm{~N}^{\mathrm{o}} 24$ (17 de septiembre, 1969): 53-54.

$180 \mathrm{~N}^{\mathrm{o}} 36$ (11 de marzo, 1970): 53. Barry Ryan se hizo conocido por la canción "Eloise" (1968).

$181 \mathrm{~N}^{\circ} 78$ (14 de julio, 1971): 53-54.

$182 \mathrm{~N}^{\mathrm{o}} 89$ (29 de septiembre, 1971): 53-54.

$183 \mathrm{~N}^{\mathrm{o}} 98$ (1 de diciembre, 1971): 54.

$184 \mathrm{~N}^{\mathrm{o}} 410$ (30 de noviembre, 1977): 52, $\mathrm{N}^{\mathrm{o}} 411$ (7 de diciembre, 1977): 52. 


\section{GUÍA MENSUAL DE ESPECTÁCULOS Y SECCIONES DE ANUNCIOS}

En 1974185 comenzó a publicarse la sección "Guía Mensual de Espectáculos", destinada a incentivar la asistencia a conciertos, obras de teatro y otros espectáculos afines. Allí se informaba acerca de festivales corales o conciertos de conjuntos como la Orquesta Sinfónica y la Orquesta Filarmónica de Chile ${ }^{186}$, programas radiales centrados en música ${ }^{187}$ o filmes de interés musical ${ }^{188}$. Interesantes resultan varias informaciones tanto en esta como en otras secciones acerca de comedias musicales, como Y el Creador dijo que se hiciera la luz que la compañía Amanecer presentaba en el teatro IEM de Santiago ${ }^{189}$, y de otro en la sección "Picadillo" que extendía la invitación para otra comedia musical, 3 Gatos en Chicarratón que se presentaba en el Teatro del Ángel ${ }^{190}$. Asimismo se publicó un reportaje acerca de una tercera comedia musical, El Principito ${ }^{191}$ y otro en torno a la obra infantil Serapio y Yerbabuena con música de Miguel Letelier ${ }^{192}$.

Encontramos además noticias acerca de visitas de intérpretes o músicos como Los Niños Cantores de Viena ${ }^{193}$, anuncios respecto de eventos como un festival en Quilicura ${ }^{194}$ o el Primer Festival de Pianistas de Sudamérica en Viña del Mar ${ }^{195}$ o anuncios de discos de intérpretes como Óscar Ohlsen ${ }^{196}$ o Barroco Andino ${ }^{197}$. Una interesante iniciativa se propuso en 1976, con el sorteo de un elepé de El Mesías de Haendel que se complementó con la publicación de la historia de esta obra ${ }^{198}$.

Un aspecto destacable es que, conforme con los propósitos de la revista, hubo intención no solo de que la joven comunidad lectora tuviese conocimientos acerca de música, la escuchara en discos o asistiera a conciertos, sino además que se involucrase en actividades musicales prácticas. El hecho que el personaje de Mampato cantara o tocara instrumentos pudo ser un estímulo tácito. En esta línea también se puede comprender la publicación puntual de avisos de clases de guitarra de Liliana Pérez-Corey ${ }^{199}$, de la Academia de Alicia Puccio $^{200}$ o información acerca de otras instancias de formación como la escuela de folclor de Patricio Ortega ${ }^{201}$. A esto podemos agregar la propuesta de construcción de instrumentos musicales caseros, específicamente una flauta en $1969^{202}$, una guitarra caminera en $1975^{203}$

$185 \mathrm{~N}^{\mathrm{o}} 225$ (15 de mayo, 1974): 52.

$186 \mathrm{~N}^{\circ} 229$ (12 de junio, 1974): 44.

$187 \mathrm{~N}^{\circ} 233$ (10 de julio, 1974): 49.

$188 \mathrm{~N}^{\circ} 237$ (7 de agosto, 1974): 49.

$189 \mathrm{~N}^{\circ} 234$ (17 de julio, 1974): 49.

$190 \mathrm{~N}^{\circ} 239$ (21 de agosto, 1974): 15.

$191 \mathrm{~N}^{\circ} 340$ (28 de julio, 1976): 28-30.

$192 \mathrm{~N}^{\circ} 402$ (5 de octubre, 1977): 40.

$193 \mathrm{~N}^{\circ} 244$ (25 de septiembre, 1974): 15.

$194 \mathrm{~N}^{\mathrm{o}} 162$ (21 de febrero, 1973): 3.

$195 \mathrm{~N}^{\circ} 236$ (31 de julio, 1974: 15.

$196 \mathrm{~N}^{\circ} 249$ (30 de octubre, 1974): 49.

$197 \mathrm{~N}^{\circ} 289$ (5 de agosto, 1975): 52.

198 No 349 (29 de septiembre, 1976): 14-16. En el mismo número se presentaron las bases del sorteo y su resultado se comunicó en el $\mathrm{N}^{\circ} 353$ (27 de octubre, 1976): 8.

$199 \mathrm{~N}^{\circ} 242$ (11 de septiembre, 1974): 15.

$200 \mathrm{~N}^{\circ} 255$ (11 de diciembre, 1974): 15.

$201 \mathrm{~N}^{\mathrm{o}} 235$ (24 de julio, 1974): 16.

$202 \mathrm{~N}^{\circ} 31$ ([24 de diciembre], 1969): 52.

$203 \mathrm{~N}^{\mathrm{o}} 302$ (4 de noviembre, 1975): 5-6) y No 303 (11 de noviembre, 1975: 4-7). 
y juegos o test musicales ${ }^{204}$. Pero la iniciativa más importante enfocada hacia este propósito fue “Aquí Cantamos Todos” que abordo a continuación.

\section{AQUÍ CANTAMOS TODOS}

En el Mampato No 56 de 1970 se inició un curso de guitarra a cargo de la "Tía Cecilia", la periodista Cecilia Eyzaguirre ${ }^{205}$, donde se entregaban las nociones básicas para iniciarse en la práctica de este instrumento, enfocado hacia músicas populares urbanas. Terminado el curso en el $\mathrm{N}^{\circ} 76$ de 1971, en el número siguiente comenzó una nueva sección en la revista destinada a prolongar el incentivo de esta práctica. Esta sección recibió el nombre de "Aquí Cantamos Todos (ACT)", la cual, si bien cambió su denominación a "Cantemos Todos" en el $\mathrm{N}^{\circ} 383$ de 1977, hasta hoy es recordada con su nombre original ${ }^{206}$. ACT permaneció en forma casi ininterrumpida hasta el $\mathrm{N}^{\circ} 256$ de 1974, reapareció en el $\mathrm{N}^{\circ} 293$ de 1975 con interrupciones más frecuentes hasta el No 378 de 1977. Como se ha dicho, a partir del N 383 de 1977 adoptó el nombre "Cantemos Todos" y permaneció hasta el último número de la revista, $\mathrm{N}^{\circ} 418$ de 1978.

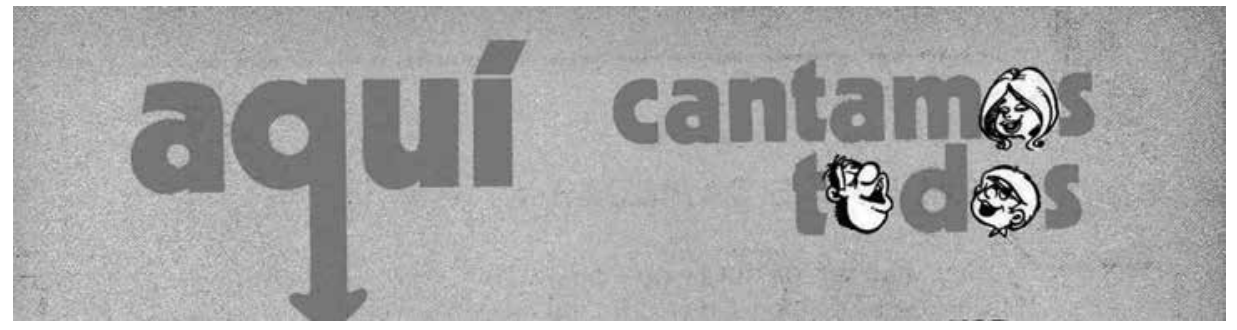

Imagen No 12: Encabezamiento de la sección "Aquí Cantamos Todos".

El correo de la revista da cuenta de la bienvenida que la mayoría de los lectores brindó a esta sección ${ }^{207}$, así como al curso de guitarra que le precedió ${ }^{208}$, en algún momento se reclamó por la reducción de su número original de páginas ${ }^{209}$ y hasta hubo solicitudes para añadir cursos de otros instrumentos musicales ${ }^{210}$. Se infiere que el propósito era recoger canciones populares clásicas y en especial canciones de moda que los lectores reconocieran y pudieran entonar con facilidad ${ }^{211}$. De casi 300 canciones que se publicaron en esta

$204 \mathrm{~N}^{\mathrm{o}} 156$ (10 de enero, 1973): 52; $\mathrm{N}^{\mathrm{o}} 162$ (21 de febrero, 1973): 49; $\mathrm{N}^{\circ} 271$ (2 de abril, 1975): $43 ; \mathrm{N}^{\circ} 282$ (17 de junio, 1975): 41.

$205 \mathrm{~N}^{\mathrm{o}} 196$ (24 de octubre, 1973): 41-44. El personaje de la marquesa Cécile de Cirulin en "Mampato y los mosqueteros" de Themo está modelado en ella (Valle 2018: 83).

206 De hecho en el índice de la revista hasta su último número figuró el título original.

207 En N 80 (28 de julio, 1971): 3, un lector solicitaba cambiar el curso de guitarra por uno de dibujo.

$208 \mathrm{~N}^{\mathrm{o}} 57$ (30 de diciembre, 1970): 3.

$209 \mathrm{~N}^{\mathrm{o}} 119$ (26 de abril, 1972): 3.

$210 \mathrm{~N}^{\mathrm{o}} 332$ (2 de junio, 1976): 8, una lectora de nombre Patricia Bustamante solicitaba un curso de flauta dulce.

$211 \mathrm{~N}^{\circ} 63$ (24 de marzo, 1971): 3; No 344 (25 de agosto, 1976): 8. 
sección con letra y acordes, prevalecen piezas en castellano, un número menor de piezas en inglés, en italiano y unos pocos casos en portugués. De este modo, aparecieron canciones de 38 músicos (entre solistas y conjuntos) chilenos, 34 españoles, 29 argentinos, 23 estadounidenses, 14 británicos, 9 italianos, 5 brasileños y un número menor de otras nacionalidades. Varios de ellos aparecieron además en la sección "Galería de Estrellas” y en algunos "Mampatogramas".

Respecto de los géneros de música popular, se aprecia predominio de la canción melódica, el rock y, en menor medida, música de raíz folclórica, Nueva Canción Chilena o neofolclor. En este sentido, la tendencia de distribución de idiomas, nacionalidades y géneros musicales en las canciones que se publicaron en ACT se aproxima a aquella identificada por Lamadrid y Baeza en su estudio acerca de la recepción de la música juvenil en Chile en los años 60, aunque la mayor parte de las ediciones de Mampato corresponda más bien a la década siguiente ${ }^{212}$. A modo de muestra, a continuación presento una tabla con los músicos de mayor presencia en la sección:

\begin{tabular}{|c|c|c|}
\hline Nombre & Nacionalidad & Frecuencia \\
\hline Julio Iglesias & Español & 9 \\
\hline Roberto Carlos & Brasileño & 8 \\
\hline Mocedades & Españoles & 7 \\
\hline Camilo Sesto & Español & 7 \\
\hline Nicola di Bari & Italiano & 5 \\
\hline Albert Hammond & Británico & 5 \\
\hline Manolo Galván & Español & 4 \\
\hline Tormenta & Argentina & 4 \\
\hline Adamo & Italiano & 4 \\
\hline Demis Roussos & Griego & 4 \\
\hline Jeanette & Hispano-británica & 4 \\
\hline Juan Bau & Español & 5 \\
\hline Los Iracundos & Uruguayos & 5 \\
\hline Rubén Mattos & Argentino & 5 \\
\hline
\end{tabular}


En cada entrega de ACT se presentaba la letra de la canción, las posturas o acordes, rasgueo y melodía en guitarra. En los primeros 33 números en que apareció la sección (en dos páginas), junto con la canción principal se presentaban las letras sin posturas de tres o cuatro canciones adicionales, a veces con una evidente unidad temática (por ej., canciones sobre la lluvia ${ }^{213}$ ) o autoral (por ej., canciones de Piero ${ }^{214}$ o canciones bossa nova ${ }^{215}$ ). Desde el $\mathrm{N}^{\circ} 112$ de 1972, la sección comenzó a presentar solo una canción con sus acordes respectivos en una sola página. Ninguna canción se repitió, excepto un par de casos en que originalmente se publicó solo la letra en las primeras 33 ediciones de la sección, y el caso curioso de la canción "I don't know how to love him" de la ópera rock Jesus Christ Superstar, publicada en inglés en el No 316 de 1976 y su versión en castellano "Es más que amor (Yo no sé cómo amarle)" en el No 351 del mismo año. Y si bien se puede apreciar errores tipográficos en algunas letras o se puede discutir el uso de algunos acordes o su sistema de notación ${ }^{216}$, resulta interesante constatar que hoy se puede recoger testimonios de miembros de la "generación Mampato" que confiesan haber aprendido o tratado de aprender guitarra con esta sección.

Es interesante notar la influencia del contexto sociopolítico en esta sección, como se ha dicho respecto tanto de la historieta principal como de las secundarias de la revista. Antes de 1973 se aprecia una diversidad ideológica en el contenido de las letras de las canciones que incluye desde canciones juveniles "inofensivas" propias de programas de televisión como Música Libre hasta canciones de Violeta Parra, Víctor Jara, Patricio Manns o Los Dos. Después de 1973, en cambio, este último tipo de repertorio desaparece.

Por otra parte, la influencia de aquellos "principios morales" o "creencias dominantes" puede notarse de modo evidente en la alteración de la letra original de la canción "Tú o nada" del español Pablo Abraira, publicada en 1977217. Mientras el estribillo original de la canción dice "Amada mía adúltera, mi gran amor, mi niña mimada", la versión publicada en Mampato dice "Amada mía tú serás mi gran amor, mi niña mimada".

Hasta qué punto estas decisiones respecto de repertorio o de alteración de letras fue decisión personal de Eyzaguirre o fue sugerencia o imposición de los directores de la revista, no he podido esclarecerlo, pero resulta evidente que el contexto político y los principios tácitos o explícitos que se buscaba inculcar a la joven comunidad lectora de Mampato influyeron en el repertorio presentado en ACT.

\section{PERSPECTIVAS}

Este 2018 se han cumplido 50 años del debut de la revista Mampato y 40 de su cancelación. Como parte de sus propósitos tanto de educación como de entretención, he mostrado

$213 \mathrm{~N}^{\circ} 88$ (22 de septiembre, 1971): 14-15.

$214 \mathrm{~N}^{\circ} 94$ (3 de noviembre, 1971): 14-15.

$215 \mathrm{~N}^{\mathrm{o}} 107$ (2 de febrero, 1972): 14-15.

$216 \mathrm{~N}^{\mathrm{o}} 171$ (25 de abril, 1973): 49. No he podido recabar información acerca de la formación musical de Cecilia Eyzaguirre. Es posible que la haya recibido en el colegio Villa María Academy, donde estudió en su etapa escolar. En N 249 (30 de octubre, 1974): 19 y No 364 (12 de enero, 1977): 8, se menciona que ella, junto con Ricardo Güiraldes, eran los músicos del equipo. Realizó además en 1976 la puesta en música de algunos poemas de Miguel Arteche Salinas (1926-2012), Premio Nacional de Literatura 1996, quien fuera subdirector de Mampato y la calificó como "juglaresa" (información en http://diario.elmercurio.com/detalle/index.asp?id=\{db26e561-e485-4687-96a8-ea03d69562f7\} y www.uchile.cl/cultura/arteche/poeticasyartic/poeticasyartic3.html [consulta: 9 de noviembre, 2018]. $217 \mathrm{~N}^{\mathrm{o}} 404$ (19 de octubre, 1977): 48. 
que prácticas, nociones y representaciones de distintos estratos y culturas musicales se presentaron en diferentes secciones de esta revista a lo largo de su existencia. Respecto de los estratos musicales, en las secciones de biografías ${ }^{218}$ y artículos especiales predomina la música académica euroclásica, es decir, el núcleo de la cultura musical occidental de acuerdo con el paradigma de la modernidad ilustrada, núcleo pretendidamente "atemporal" en su condición de patrimonio de la humanidad. En cambio, en la sección "Aquí Cantamos Todos" predominan las músicas populares urbanas, las canciones de moda y sujetas a la contingencia del contexto sociohistórico y político. Lo importante es que esta última sección apuntaba al incentivo directo de la práctica musical.

Recordemos que hasta 1973 se aprecia una evidente intención de apertura en la revista Mampato que en sus inicios incluía hasta noticias acerca de la realidad mundial, a veces presentadas con alta "crudeza" de la realidad ${ }^{219}$. Esta apertura se aprecia en la inclusión de canciones de distinto contenido ideológico en ACT o de artistas de diferentes posturas políticas en "Galería de Estrellas". Como se ha mencionado, después de 1973 esto cambió.

En el caso de las historietas, tanto Mampato como las demás historietas secundarias que se publicaron en la revista, se observa la presencia de una "red de citas" que remite a diferentes mundos y estratos musicales. Y en esa red también se asoma la contingencia sociopolítica de aquellos años. Después de 1973 no se vuelve a ver el afiche de Ángel Parra en el dormitorio de Mampato como ocurre al comienzo de "Mampato y Rena en el siglo XL", pero en 1977 se cita a Violeta Parra en "Los suterones" y a Guidú se le permite publicar esa historia de Chepita con evidentes alusiones a músicos o canciones que habían sido o serían relegados a una lista negra.

Al considerar Mampato como fuente para estudios musicológicos o culturales, se vislumbran diversas líneas de investigación vinculadas con la relación entre músicas, narrativa e historietas, las escenas musicales y la circulación de repertorios en Chile entre 1968 y 1978, el perfil biográfico de músicos, artistas e investigadores, entre otras. Y por supuesto, se abre la opción de revisar publicaciones como El Peneca o Cabrochico u otras revistas similares en Chile o en Latinoamérica desde este enfoque de interés.

Señalaré finalmente que la misma "generación mampatina" que se ha encargado de digitalizar todos los números de Mampato y compartirlos en diferentes sitios web, organizar encuentros y realizar comentarios de apreciación de sus historietas y secciones, ha proseguido la publicación de la revista con números digitales que continúan tanto la numeración como las historietas y otras secciones que tenía Mampato en el momento de su cancelación. De este modo, hasta ahora han editado 13 números "adicionales", desde el $\mathrm{N}^{\circ} 419$ al 431. En los Nos 420 al 429 han incluido una "Historia de la música" con dibujos que Themo Lobos hizo para otra publicación, en el $\mathrm{N}^{\circ} 422$ se incluyó una página de caricaturas musicales de Claude Serre, y en los Nos 428, 429 y 431 reaparece "Aquí cantamos todos" con "Cuando era guailón" de Payo Grondona, "Latin Blues" de Santiago del Nuevo Extremo y "Violeta ausente" de Violeta Parra. Ciertamente estas tres canciones difícilmente hubieran podido ser publicadas en Mampato después de 1973, pero podríamos asumir que se trata de canciones que muchos mampatinos hubieran querido que se publicaran. Lo que confirma que la revista Mampato, en sus diferentes secciones, logró no solo que el conocimiento acerca de las músicas sino la práctica musical, hacer o escuchar, fuera significativa para toda una generación.

218 Una excepción fue una biografía de la familia Von Trapp en № 357 (24 de noviembre, 1976): 14-16.

219 Por ej., comentario respecto del conflicto árabe-israelita en $\mathrm{N}^{\mathrm{o}} 10$ (1969): 49, presenta foto de ahorcados. 


\section{BIBLIOGRAFÍA}

Alvarracín Espinoza, Andrea y María José GonzÁlez Ávila

2015 Efectividad del cómic en revistas infantiles educativas. Trabajo de graduación previo a la obtención del título de Licenciado en Comunicación Social y Publicidad. Cuenca (Ecuador): Universidad del Azuay.

Armstrong Irarrázaval, Jorge

2015 "Ausencia presente", Armstrong. Retrato de su obra visual. Eduardo Armstrong Aldunate, edición dirigida por Jorge Armstrong Irarrázaval. Santiago: Ograma Impresores, p. 9.

Arroyo Cabello, María

2006 "El consumo de revistas juveniles entre los menores", La ética y el derecho en la producción y el consumo del entretenimiento. Valencia: Fundación COSO de la Comunidad Valenciana para el Desarrollo de la Comunicación y la Sociedad, pp. 111-121.

Ballesteros Aguayo, Lucía

2018 "La prensa católica de Franco: ¡Zas! Un modelo de revista infantil (1945)”, RIHC: Revista Internacional de Historia de la Comunicación, 10, pp. 268-285.

Barrero Martínez, Manuel

2015 Sistemática de la historieta. Aplicación al caso de la historieta y el humor gráfico en Sevilla: 1864-2000. Tesis doctoral. Universidad de Sevilla.

Block, Alan A.

2000 "Leer revistas infantiles: cultura infantil y cultura popular", Cultura infantil y multinacionales. Editado por Shirley R. Steinberg y Joe Lyons Kincheloe. Madrid: Morata, pp. 153-162.

Castillo Fadic, Gabriel

2013 "Función heroica y anticipación tecnológica en la historieta infantil chilena, en el ocaso del Estado educador", Revista de Humanidades, 28 (julio-diciembre), pp. 167-186.

2018 "El proyecto Mampato (1968-1978). Representaciones de anticipación tecnológica en el ocaso de una modernidad marginal", Tebeosfera, tercera época, 8. Disponible en www. tebeosfera.com/documentos/el_proyecto_mampato_1968-1978_representaciones_de_anticipacion_tecnologica_en_el_ocaso_de_una_modernidad_marginal.html.

Escalante Fernández, Carlos

2015 "Niñez, familia y prensa en la segunda mitad del siglo XIX en México", Actas de las 4tas Jornadas de Estudios sobre la Infancia. Buenos Aires, pp. 160-177.

EsPiño Rosende, MARÍa Jesús

2014 "Las revistas infantiles como producto de consumo y medio publicitario", Actas Icono, 14-15, Congreso Internacional de Comunicación Infantil. Madrid: Asociación Científica de Comunicación y Nuevas Tecnologías, pp. 69-84.

FAlabella, Mariel

2009 "El cuerpo de la(s) lectura(s). Imágenes del niño lector en la revista Billiken 1976-1983", Questión, I/21, pp. 1-7.

Falabella, Mariel y Gaspar Flavio Tomino

2007 "La construcción de modos de figuración del cuerpo infantil en las publicidades de Billiken", Memorias de las XI Jornadas Nacionales de Investigadores en Comunicación. Mendoza: Universidad de Cuyo.

González Rodríguez, Juan Pablo y José Miguel Varas Morel

2005 En busca de la música chilena. Crónica y antología de una historia sonora [Cuadernos Bicentenario]. Santiago: Publicaciones del Bicentenario. 
GonZÁlez Villacís, KAREN

2015 Influencia de las revistas infantiles en la percepción y comportamiento de los niños: caso de la revista La Pandilla, en relación a las revistas Elé y Veo Veo. Proyecto de Titulación para la obtención de Licenciatura en Comunicación. Facultad de Comunicación. Quito: Universidad de los Hemisferios.

Hasson, MoIsés

2014 Comics en Chile. Catálogo de revistas (1908-2000). Santiago: Nauta Colecciones.

Jackson Albarrán, Elena.

2015 "Los niños colaboradores de la revista 'Pulgarcito' y la construcción de la infancia, México 1925-1932”, Iberoamericana, X/60, pp. 155-168.

Jofré, Manuel Alcides

1986 Publicaciones infantiles y revistas de historietas en Chile. Santiago: CENECA.

LAmadrid Álvarez, Silvia

2014 Ritmo revisitado. Representaciones de género en los 60. Santiago: Cuarto Propio.

Lamadrid Álvarez, Silvia y Andrea Baeza Reyes

2017 "La recepción de la música juvenil en Chile en los años 60: ¿americanización de la juventud?", Revista Musical Chilena, LXXI/228 (julio-diciembre), pp. 69-94.

LoLAs Escárate, JAZMíN

2015 "Biografía", Armstrong. Retrato de su obra visual. Eduardo Armstrong Aldunate, edición dirigida por Jorge Armstrong Irarrázaval. Santiago: Ograma Impresores, pp. 13-20.

Mendívil Trelles, Julio

2016 En contra de la música. Herramientas para pensar, comprender y vivir las músicas. Buenos Aires: Gourmet.

Olivera, Ignacio

2014 Las revistas didácticas infantiles en Buenos Aires. Su lugar entre los consumos culturales de los niños. Trabajo de graduación en Licenciatura en Comunicación, Departamento de Ciencias Sociales. Buenos Aires: Universidad de San Andrés.

Ortega Ruiz, Francisco

2018 "El Multiverso Mampato”, Los increíbles viajes de Mampato. Óscar Vega Etcheverry. Santiago: Planeta Cómic, pp. 11-14.

Ospina Canencio, Cielo Erika

2017 "Lectores imaginados por las revistas infantiles: Chanchito, revista semanal ilustrada para niños y Mamita, revista semanal de cuentos infantiles", Revista de Humanidades, 35 (enerojunio), pp. 103-155.

Pascual Gómez, Julia

2018 De La Chacha a Mamurra: La construcción de lo femenino a través de la historieta infantojuvenil durante los siglos XX y XXI. Tesis de Magíster en Literatura para Niños. Rosario: Universidad Nacional de Rosario, Facultad de Humanidades y Artes.

Pérez González, Juan Diego

1999 "Las revistas infantiles y juveniles de carácter educativo en España. Una visión general para nuestro tiempo", Educación y Medios de Comunicación Social: Historia y Perspectivas. Sevilla: Real Sociedad Sevillana de Amigos del País, Universidad de Sevilla, pp. 143-145.

Peters, Victoria y Milena Trujillo Acosta

2018 "Rin Rin, revista infantil del ministerio y Chanchito, revista ilustrada para niños. La dimensión de sus imágenes. Dos revistas de ideologías contrarias publicadas durante la década de los treinta en Colombia", Análisis, L/92 (enero-junio), pp. 119-143. 
Robledo, Beatriz Helena

2004 "La revista Chanchito, un homenaje a los niños colombianos", Boletín Cultural y Bibliográfico, XLI/67, pp. 35-52.

Rojas Flores, Jorge

2010 Historia de la infancia en el Chile republicano, 1810-2010. Santiago: Junta Nacional de Jardines Infantiles.

2012a "Representaciones de la infancia en el espacio de las historietas, 1900-1980", Revista Chilena de Pediatría, LXXXIII/6, pp. 608-616.

2012b Estrategias de poder y valores políticos en Mampato (1968-1978)”, Mapocho, 71, pp. $297-314$.

2012c "Lucha política y conciliación de clases en una revista de historietas: el caso de Mampato, 1968-1978”, Dossier Chile contemporáneo, Revista Historiapolitica.com. Coordinado por Verónica Valdivia. Disponible en: http://historiapolitica.com/dossiers/chile-contemporaneo/

2016 Las historietas en Chile 1962-1982. Industria, ideología y prácticas sociales. Santiago: LOM/DIBAM.

Tessada Sepúlveda, Vanessa

2009 "El Peneca y Billiken. Ser niño en Chile y Argentina a principios del siglo XX", América Latina en el nuevo milenio: procesos, crisis y perspectivas. Editado por Elena Oliva y otros. Santiago: Centro de Estudios Culturales Latinoamericanos, Universidad de Chile, pp. 17-37.

Valle Muñoz, Rafael

2018 La gran aventura de Themo Lobos. Santiago: Sudamericana.

Vega Encina, FÉLix

2018 "Mampato en la memoria”, Los viajes en el tiempo de Mampato. Óscar Vega Etcheverry. Santiago: Planeta Cómic, pp. 7-10.

Vega Etcheverry, Óscar

2018 "Óskar", Los viajes en el tiempo de Mampato. Óscar Vega Etcheverry. Santiago: Planeta Cómic, pp. 155-157.

WARnken Lihn, Cristián

2015 "Las islas del tesoro de Armstrong. Impresiones personales". Armstrong. Retrato de su obra visual. Eduardo Armstrong Aldunate, edición dirigida por Jorge Armstrong Irarrázaval. Santiago: Ograma Impresores, pp. 111-116. 